\title{
¿El canto a San Francisco o las exequias de Sebastián Ramírez de Fuenleal? Una aproximación al llamado Pipilcuicatl o "Canto de niños" del manuscrito de Cantares mexicanos
}

Katarzyna Szoblik Instituto de Estudios Ibéricos e Iberoamericanos, Universidad de Varsovia Instituto Polaco de Investigación de Arte Mundial

\section{EL TRASFONDO HISTÓRICO}

El encuentro de dos mundos que se produjo con la llegada de los europeos al continente americano marcó un principio de la época de contactos culturales muy intensos. Uno de los primeros choques que se dieron fue la conquista de Tenochtitlan y las regiones controladas por ella por las tropas de Hernán Cortés en 1521. Puesto que la campaña misma, así como todas las cruelades cometidas por los españoles durante y después de ella, eran justificadas por el celo evangelizador, una de las primeras peticiones dirigidas por Cortés al rey de España, Carlos I, fue la de enviar a México a los misioneros que emprendieran lo que Robert Ricard llamó "la conquista espiritual" de los indígenas. ${ }^{1}$ En consecuencia, ya en 1523 los primeros tres frailes franciscanos, Pedro de Gante, Juan de Tecto y Juan de Ayora, desembarcaron en el puerto de Veracruz y se dirigieron hacia el Altiplano Central. En Texcoco, donde al principio fueron alojados por Cortés, tuvieron la oportunidad de observar a los indígenas y darse cuenta de

\footnotetext{
${ }^{1}$ RICARD 2014.
} 
que el único método eficaz de cristianizarlos era a través de sus propios modelos culturales, adaptados a las verdades de la fe católica. Como consecuencia, este mismo año, los frailes fundaron el Colegio de Texcoco, donde empezaron a reunir a los niños de la nobleza indígena para enseñarlos “... a leer y escribir, cantar y tañer los instrumentos musicales, y la doctrina cristiana" ${ }^{\text {" }}$. Al mismo tiempo aprendían de ellos las lenguas nativas y recogían información sobre los antiguos usos, costumbres y creencias. Al trasladarse al Convento de San Francisco, establecido en 1525 en la Ciudad de México, Pedro de Gante fundó la capilla abierta de San José de los Naturales, "uno de los principales centros educadores y evangelizadores de indios hasta la construcción de Santiago Tlatelolco." ${ }^{3}$ Es allá donde, gracias al patio abierto al estilo antiguo, se organizaba la evangelización a escala masiva. Con la ayuda de sus estudiantes indígenas Gante reunió varias muestras de la tradición oral prehispánica para aprovechar sus modelos formales y recursos estilísticos en la creación de los sermones, catecismos y cantos en honor a Dios y a los santos. Anales de Juan Bautista, un texto nahuatl de mediados del siglo XVI, informa sobre varias fiestas cristianas celebradas con adornos tradicionales y cantos entonados en lengua náhuatl. Entre ellas se menciona la siguiente:

"Septiembre de 1567, entonces estudiaron el canto la gente de la iglesia, estudiaron el pipilcuicatl, allá en el templo estudiaban por mandato de nuestro padre fray Pedro de Gante, dijo: se interpretará cuando salga la fiesta de San Francisco, convocaré a todas partes. ¿Qué pensarán de nosotros las gentes de todos los pueblos? Y la gente de la iglesia daba de comer en el templo a los cantores macehuales para enseñarlos. Y cuando se celebró la fiesta de San Francisco, en sábado, precisamente entonces se interpretó. Los que hicieron bailar a la gente, fueron la gente de la iglesia, Francisco Quetzalayatl, Francisco Matlalacaca, Andrés Motecpillitohua, Juan Totococ y Juan Martín. Y cargaron insignias, casco y escudos $(\ldots)$ y los ornamentos sagrados, dalmáticas de dos tipos, una amarilla y otra colorada." 4

El canto del mismo nombre, que será objeto de estudio en el presente trabajo, se encuentra registrado en el manuscrito proveniente del último cuarto del siglo XVI, titulado Cantares mexicanos -una colección de textos en náhuatl de origen, temática y grado de europeización muy variados-. Aunque en ninguna parte ostenta el nombre del recopilador de los cantos registrados en ese

\footnotetext{
${ }^{2}$ Mendieta 1999: 608.

LÓPEZ DE LA TORRE 2016: 5.

${ }^{4}$ ReYes GarCía 2001: 164-165.
} 
manuscrito, se supone que fue obra de otro franciscano famoso, Fray Bernardino de Sahagún, y sus ayudantes indígenas. ${ }^{5}$

En el folio 46r de este manuscrito está escrito:

"Nican onpehua yn Pilcuicatl ahnoço Piltoncuicatl ye huecauh meuh ompa Mexico S. frro ypan ilhuitzin tomatian mochiuh yquac in ompa teopan tinemia oc tipipiltotontli

Aquí empieza el canto de niños (pilcuicatl), o canto de niños pequeños de los tiempos pasados. Se levantó allí en México en la fiesta de San Francisco en nuestros tiempos. Se hizo cuando todavía vivíamos allí en la casa de Dios, nosotros los niñitos". ${ }^{6}$

Las concordancias tanto en el título del canto, como en la información acerca del contexto de su representación -la fiesta de San Francisco- parecen indicar que en ambos casos se trata de la misma obra. Sin embargo, como se verá en adelante, tanto las referencias históricas, como la imaginería metafórica de esa obra sugieren que su entonación no estaba pensada solamente para festejar a San Francisco.

\section{El ANÁLISIS DEL CANTO}

El "Canto de niños" ocupa los folios 46r-48r y está dividido en diez partes, cuyo inicio está marcado por las cadencias de tambor. La primera secuencia abre con el llamamiento al canto, una fórmula que se repite en numerosos cantos del manuscrito y parece formar parte fija de la tradición oral nahua. Es lo que Walter Ong $^{7}$ indica como uno de los rasgos distintivos de las creaciones orales en general, una herramienta destinada a atraer y enfocar la atención de la audiencia.

\section{"Cototicoto ticoto tiquiti cototiquiti cototiquiti}

Ya man toncuicatlatocan tihuexotzinca, ma toncuicapepehuacan aya xochitl totlayocol in tocõyachihuazque in tipipiltzinti ma onahahuialon amoxcalli manicã. Ya cuel conetle

ma xihuallacã Antepilhuã y ma oncuicatlatlanihua anqui ya nicã y acon y ye quichiuh ilhuicatl yn tlalticpac aya o anqui ya yehuatl totatzin Dios aya ontlaneltoca toyollon tipipiltzitzinti ma onahahuialon amoxcali manicã ya cuel conetle

\footnotetext{
5 LeÓn-Portilla et al. 2011, I: 180-183.

${ }^{6}$ Cantares Mexicanos 1994 fol. 46 r, trad. de la Autora.

7 ONG 1982.
} 
¡Entonemos el canto, nosotros los huexotzinca, empecemos el canto! Haremos las creaciones floridas, nosotros los niños. ¿Que haya gozo en la casa de libros! ¡Presto aquí, oh niño!

¡Venid, oh niños! Se piden cantos. Aquí está, ha llegado El que Hizo el Cielo y la Tierra. Aquí está, ha llegado nuestro Padre Dios. Es lo que creen nuestros corazones de niños. ¡Que haya gozo en la casa de libros! ¡Presto aquí, oh niño!”8

"La casa de libros" mencionada en este fragmento es el Convento de San Francisco, donde los niños indígenas eran educados con la ayuda, entre otros, de los catecismos pictóricos. Era también el lugar donde se organizaban las fiestas religiosas a gran escala y del que partían varias procesiones [figs. 1 y 2].

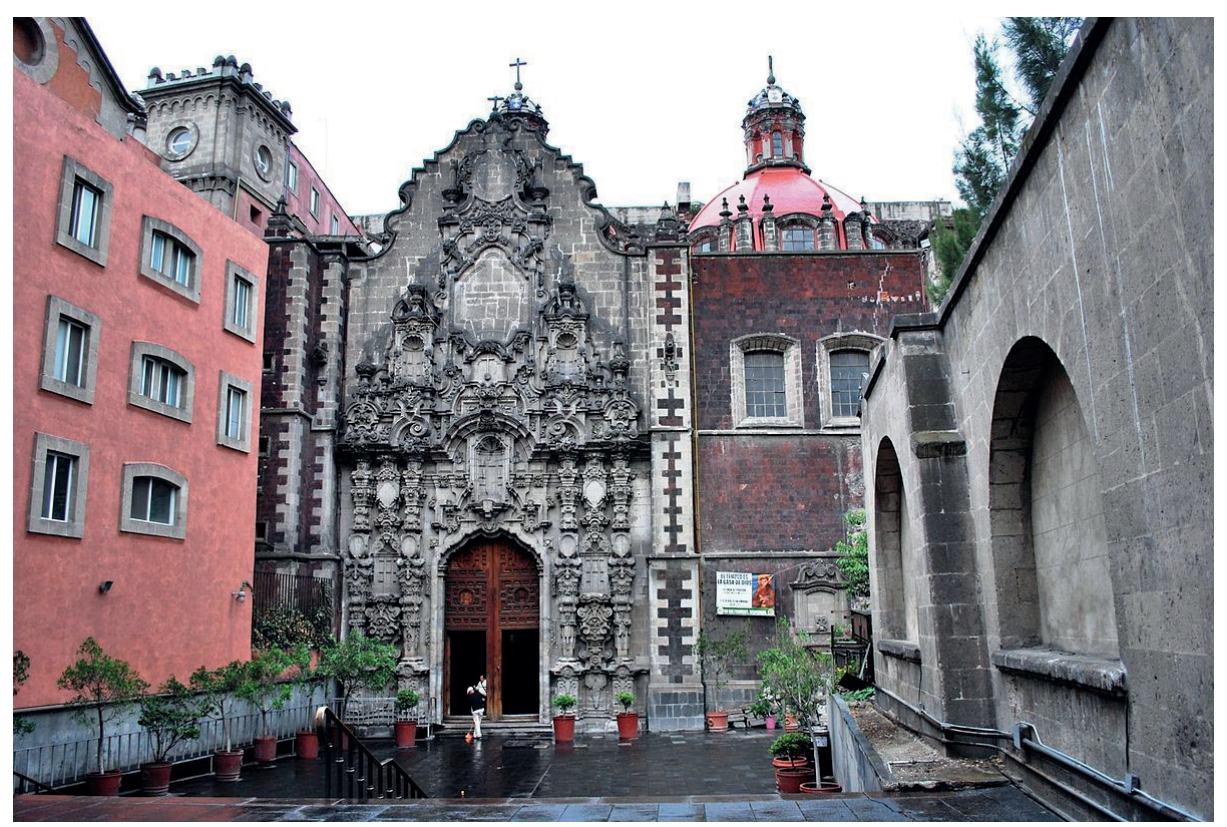

Fig. 1. El templo y exconvento de San Francisco de la Ciudad de México, 1710-1766, México.

${ }^{8}$ Cantares mexicanos 1994, fol. 46r, trad. de la Autora. 


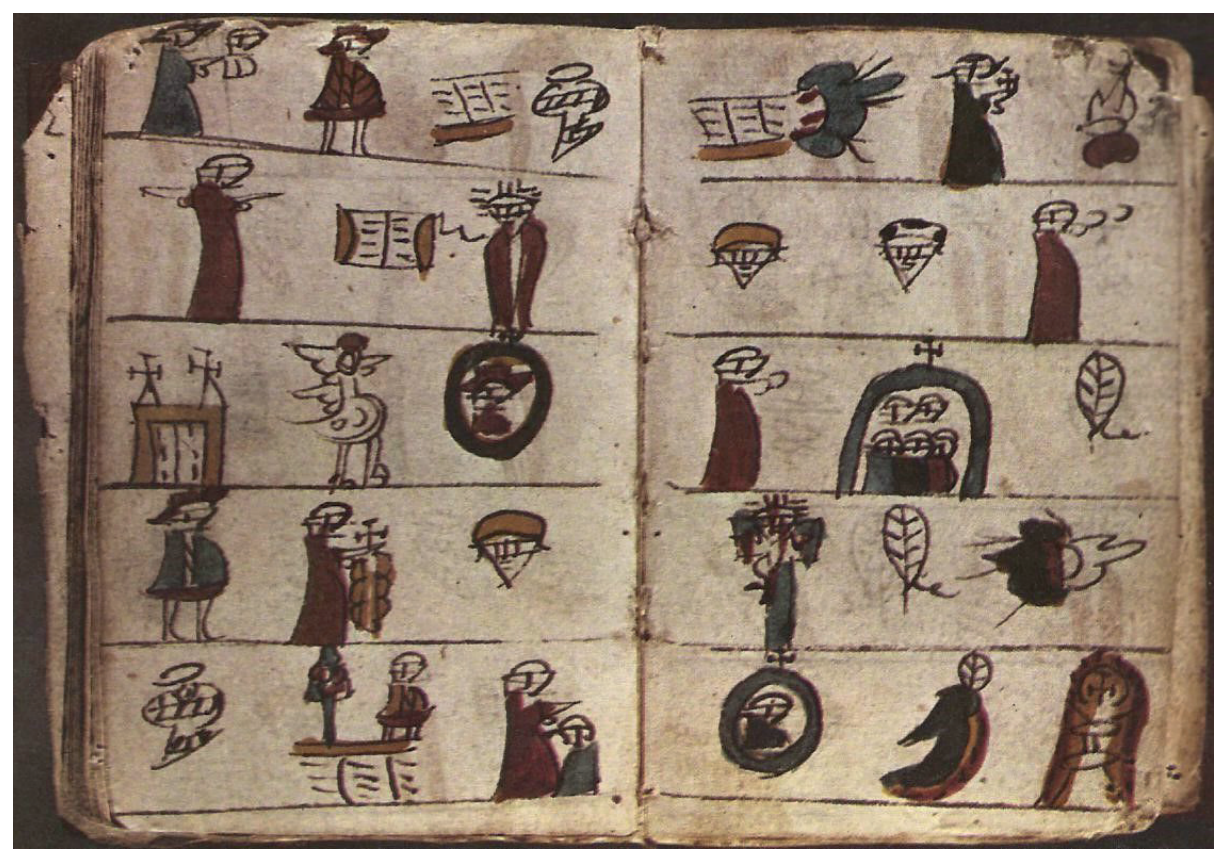

Fig. 2. Una hoja del catecismo pictórico popularmente atribuido a Pedro de Gante, Biblioteca Nacional de Madrid, Ms. Vit. 26-9.

La invocación al Dios Cristiano "El que Hizo el Cielo y la Tierra" es una traducción directa del Salmo 146:6 y una cita del Credo Niceno Constantinopolitano. ${ }^{9}$ Forma parte de una afirmación de la fe expresada con las palabras ontlaneltoca toyollon - "(Es lo que) creen nuestros corazones". En otras palabras, esos versos iniciales presentan un discurso típicamente cristiano, que a primera vista se mantiene también en las líneas que siguen:

O xiuhquecholchoocan tlatoa ye noyollo çan niquelnamiquia yn anpipiltzitzinte tomachhuane queihuelço tehua a ye ticmahuiçohua yn itlatol y ilhuicatl yyollo dios mochiuhtoquin cayio.

Yn ma ontlaocoyelon titocnihua anpipiltzitzinte tomachvane $\hat{y}$ teocuitlaticaya cecenpoalxochin-tlatlahuizcallehuatoc ye iquelesia yn oncã notzalo ontlatlauhtilo ya ylhuicatl yiollon dios mochiuhtoquin caiyo.

Canta mi corazón, llora por el ave xiuhquechol, sólo lo recuerdo. Oh niños, oh nuestros sobrinos, bienaventurados somos nosotros, los que nos asombramos ante la palabra de Dios, el Corazón del Cielo, El que se Ha Hecho a Sí Mismo. ¡Entristezcámonos, oh amigos! ¡Vosotros, oh niños, oh sobrinos! Con el oro se extiende el alba en el jardín de flores

\footnotetext{
9 La Biblia de las Americas 1997; CRedo S.F..
} 
cempoalxochitl. Allá, en la iglesia es llamado, es rogado Dios, el Corazón del Cielo, El que se Ha Hecho a Sí Mismo. ${ }^{10}$

La invocación cristiana, marcada sobre todo por la incorporación de la palabra castellana "Dios", está sumergida entre varias fórmulas provenientes de la tradición prehispánica. Para empezar, la invocación a Dios que lo titule "el Corazón del Cielo, El que se Ha Hecho a Sí Mismo" si bien puede ser una alusión a otra parte del Credo, referente a Jesucristo como "...engendrado, no creado, de la misma naturaleza del Padre, por quien todo fue hecho", está presente, y en forma mucho más literal, también en la tradición indígena. Me refiero a la descripción de la creación del mundo proporcionada por el libro sagrado de los k'iché conocido como Popol Vuh. El narrador de la misma se refiere a las divinidades creadoras principales del modo siguiente:

Lo que podría existir simplemente no existe: sólo los murmullos de olas pequeñas en la oscuridad, en la noche. Sólo el Creador, sólo el Modelador, el Soberano - La Serpiente Emplumada, los Portadores, los Progenitores están en el agua, la luz reluciente. (...) Y por supuesto el cielo ya está allí, y ya está también el Corazón del Cielo. Este, como dicen, era el nombre de dios. ${ }^{11}$

"El Corazón del Cielo" mencionado por el texto maya es el Sol. En el discurso evangelizador novohispano Dios, sobre todo en el acto de su Encarnación, también aparece como simbólicamente vinculado a este astro, por lo cual esa fusión del término originalmente indígena con el concepto cristiano parece natural.

El fragmento analizado presenta, además, ciertas fórmulas sacadas de la tradición prehispánica de los cantos de conmemoración de los señores y/o guerreros difuntos, cuyas muestras se encuentran en otras partes del manuscrito de Cantares mexicanos. La primera es: "Canta mi corazón, llora por el ave xiuhquechol, sólo lo recuerdo." Los verbos choca "llorar" e ilnamiqui "recordar" aparecen en varios cantares, formando una suerte de molde modificable (p.ej. el que llora puede ser el cantor, su corazón u alguna otra persona), pero obligatorio en las obras de este tipo. ${ }^{12}$

${ }^{10}$ Cantares mexicanos 1994, fol. 46v, trad. de la Autora

11 TeDlock 1996: 64-65, trad. de la Autora.

12 Ejemplos de los cantos donde aparece esta formula se encuentran, entre otros en los folios: $4 \mathrm{v}, 5 \mathrm{v}, 31 \mathrm{v}, 35 \mathrm{r}$ del manuscrito. 


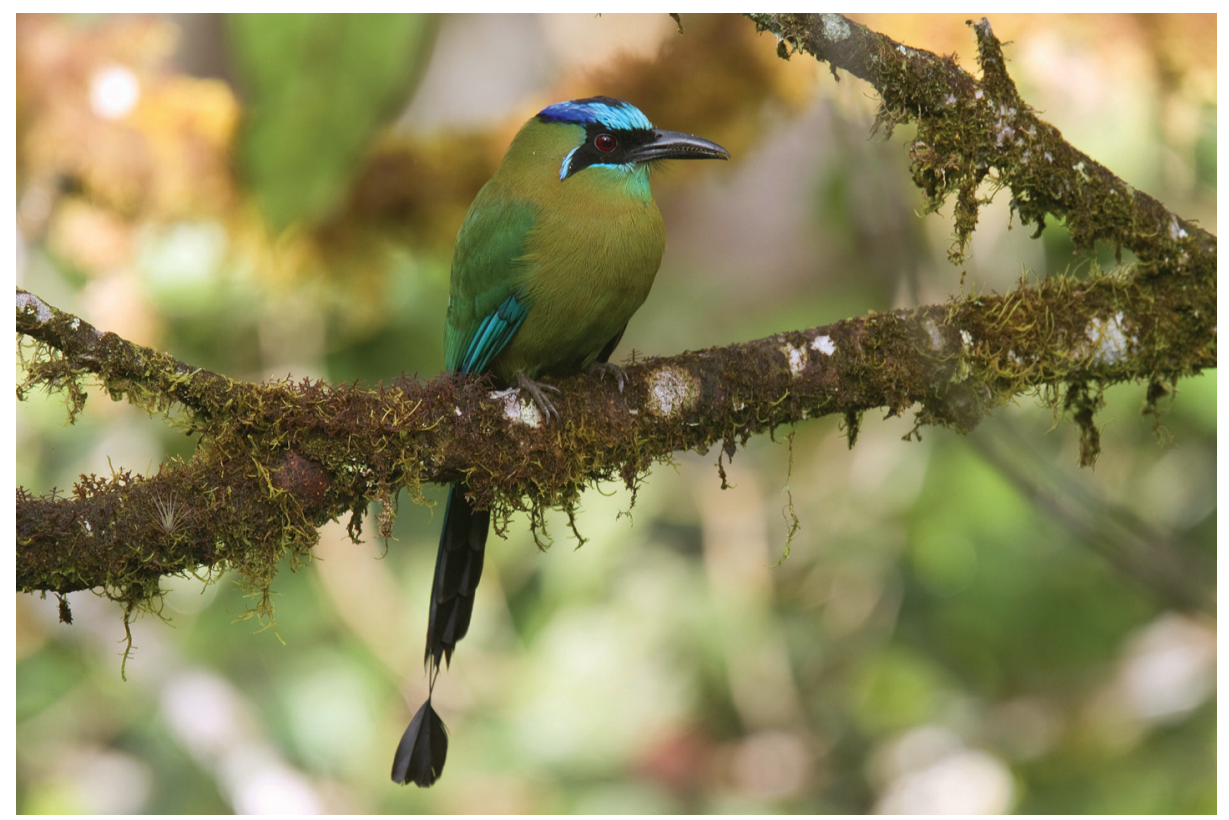

Fig. 3. Momoto diademado (Momotus lessonii), en náhuatl: xiuhquecholli, Costa Rica, fot. Henrik Bringsøe.

El ave xiuhquechol, literalmente "un quecholli de color turquesa", identificado por los investigadores como momoto diademado ${ }^{13}$ [fig. 3], en la estética nahuatl pertenecía a las tlazototome, "aves preciosas", que designaban a los guerreros muertos en la batalla o en la piedra de sacrificio. Esos valerosos pasaban al más allá de eterna felicidad y gloria. De acuerdo con las creencias indígenas:

Todos éstos dizque están en un llano, y que a la hora que sale el Sol alzaban voces y daban grita, golpeando las rodelas. Y el que tiene la rodela horadada de saetas, por los agujeros de la rodela mira al Sol. Y el que no tiene la rodela horadada de saetas no puede mirar el Sol. Y en el Cielo hay arboleda y bosque de diversos géneros de árboles. (...) Y después de cuatro años pasados, las animas destos defunctos se tornaban en diversos géneros de aves de pluma rica y color, y andaban chupando todas las flores ansí en el Cielo, como en este mundo... ${ }^{14}$

13 Wimmer 2014, en: G.D.N. (Gran Diccionario en Nahuatl) 2011, programa de Marc Thouvenot, bajo la entrada: xiuhquechol. Identificación a partir de la descripción ofrecida por los informantes de Sahagún en el Códice Florentino (SAHAGún1950-1982, XI: 20).

${ }^{14}$ SAhagún 1988, I: 222-223. 
El ave xiuhquechol, al que el cantor recuerda y por el que llora, parece pues la primera pista que indica hacia el papel conmemorativo de este canto, similar al de los cantares prehispánicos entonados, entre otros, en las exequias de la nobleza mexica. ${ }^{15}$ La identidad del personaje al que el cantor se refiere con este término glorioso permanence velada en esta primera parte del texto. Las referencias mortuorias están visibles también en la frase: "Con el oro se extiende el alba en el jardín de flores cempoalxochitl". Como se ha visto en la cita anterior, los guerreros glorificados por la muerte en la batalla esperaban al Sol en el lugar de su salida, en el Oriente. Por lo tanto, la imagen del alba que se extiende entre las flores amarillas de cempoalxochitl en su sentido original podía referirse ese lugar.

En la época colonial, los frailes que tuvieron que enfrentarse al problema de trasmitir las verdades de la fe cristiana con los términos de la lengua náhuatl, con entusiasmo recibieron estas visiones del más allá indígena lleno de flores y pájaros, tan parecido a la visión del paraíso cristiano descrito por el Génesis [fig. 4]. ${ }^{16}$

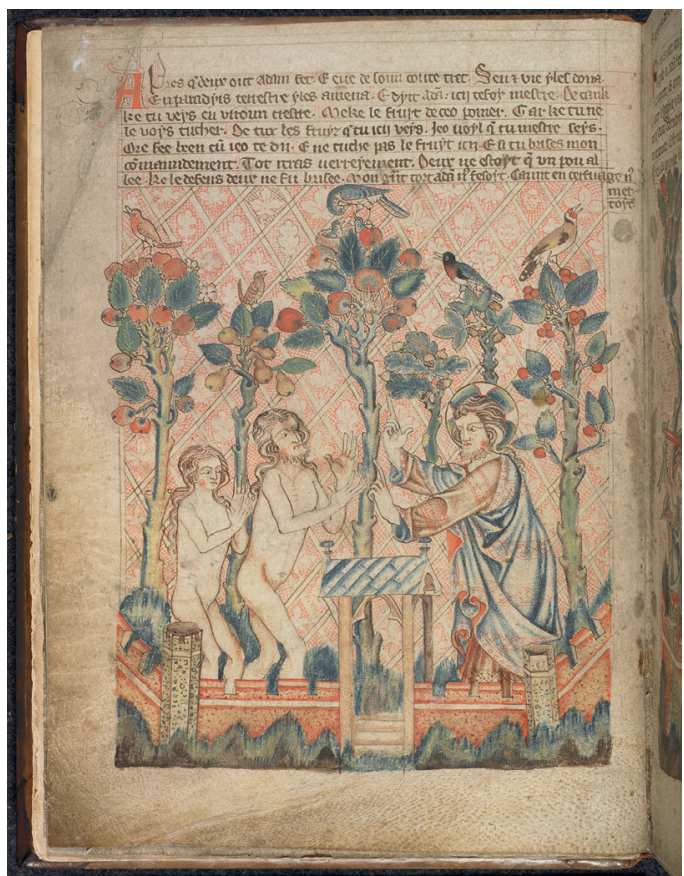

Fig. 4. El jardín del Paraíso según las imágenes de Holkham Bible (siglo XIV).

${ }^{15}$ Las exequias de la nobleza mexica las menciona por ejemplo: Alvarado Tezozomoc 2001: 236-238, 404.

${ }^{16}$ La Biblia de las Américas 1997, Génesis 2:8-9. 
Como consecuencia, en el discurso evangelizador temprano las fórmulas orales antes utilizadas para referirse a la Casa del Sol fueron resemantizadas: la llanura florida del Este se convirtió en la metáfora del paraíso cristiano, la salida del Sol fue simbólicamente vinculada al nacimiento del Cristo, y las aves preciosas llegaron a representar las almas de los salvados, o a veces también a los ángeles. ${ }^{17}$ Elementos de este programa artístico, están visibles, entre otros en las pinturas murales del ex-convento augustino del Divino Salvador en Malinalco [fig. 5].

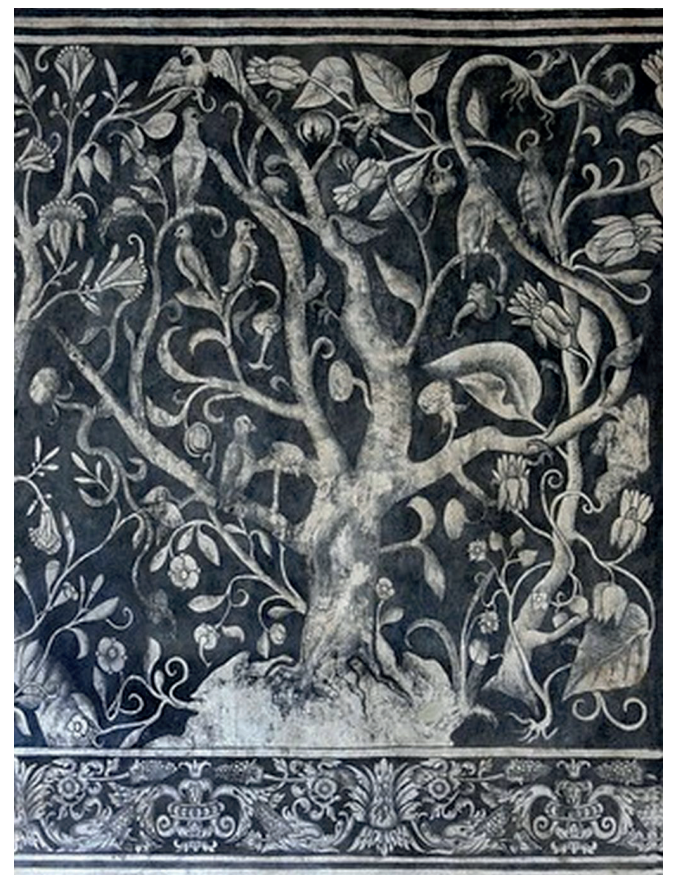

Fig. 5. El paraíso lleno de flores, árboles y pájaros, pintura mural en el ex-convento augustino del Divino Salvador en Malinalco, el siglo XVI, México.

El fragmento analizado termina con la descripción de la noche horrorosa que, de acuerdo con el discurso metafórico de la Biblia, precedía el nacimiento de Cristo:

Yye o çan ayohuica nemohuaya anayan tlatlayohualpan tlalticpac ayac huelonqui ynicya tiazque tlatzontequiz totecuyo Dios yn ipalontinemi tocnihuane tocnihuane xompaquica hue ceyohual in tlatzontequin Dios onteyttohua onteyhua ca ompa ximoa tocnihuane tocnihuane xompaquica hue.

17 Burkhart 1992. 
Sueltamente se vive en la oscuridad que se extiende en la superficie de la tierra. Nos iremos, lo juzgará nuestro señor Dios, El por Quien vivimos, oh amigos nuestros, oh amigos nuestros, jalegráos! Durante la noche Dios dicta las sentencias, mira desde arriba a la gente, envía a la gente al lugar donde se descarna a las personas, oh amigos nuestros, oh amigos nuestros, ¡alegráos! ${ }^{18}$

A esa imagen de la humanidad que erra en la oscuridad y está sometida a las sentencias justas pero terribles de Dios, que la mira desde la altura de su trono, agregaron los frailes una referencia a otro de los más allá indígenas: Ximoayan, "El Lugar donde se Rapa/Descarna a la Gente". De acuerdo con las creencias antiguas, las personas que morían por causas naturales, como la vejez, iban al lugar de los muertos, llamado Mictlan, conocido también como Quenonamican, "Lugar Misterioso" o Ximoayan. Según las informaciones proporcionadas por los informantes de Sahagún, era un espacio completamente distinto de la Casa del Sol. Para llegar al lugar de su reposo final los muertos tenían que atravesar primero por varios peligros: las montañas que se juntaban para aplastar a la gente, el camino lleno de culebras, los desiertos, las sierras, el lugar donde siempre soplaban los vientos de filo de obsidiana y el río enorme. ${ }^{19}$ Cuando finalmente llegaban ante los dioses del inframundo, Mictlantecuhtli y Mictecacihuatl, quedaban completamente descarnados. Tomando en cuenta esta información, no es de extrañar que en la óptica europea de los frailes este lugar resultó muy parecido al infierno cristiano o Seol judío, y como tal empezó a ser empleado en los textos doctrinales [figs. 6 y 7]. De este modo, la primera parte del canto termina con la visión de las almas humanas errantes, enviadas al abismo por el Dios-Juez Todopoderoso.

La segunda parte del canto cambia un poco de tema:

\section{Tocotiqui tocoti tocotiqui tocoti tiquitiquitiquito tiquitiquitiquito}

On opehualoc.S. Palacisco ye cuicoya tidon Jihua o ye titztlolincaton i ma ye tocontocaca ye totata in Pelesitente ye quitlatlauhtia ycelteotl in tipipiltzinti maoc tonahahuiaca o anqui ye nica an a.

Ya se ha dado el comienzo [en] San Francisco, ya se canta,joh, don Juan Itztlolinqui pequeño! Enterremos ya a nuestros padre, el Presidente. Él ya ruega al Dios Único. Holguemos nosotros, los niños, todavía un rato aquí. $^{20}$

\footnotetext{
18 Cantares mexicanos 1994, fol. 46 v, trad. de la Autora.

19 SAhagún 1950-1982, III: 42-44.

${ }^{20}$ Cantares mexicanos 1994, fol. 46v, trad. de la Autora.
} 


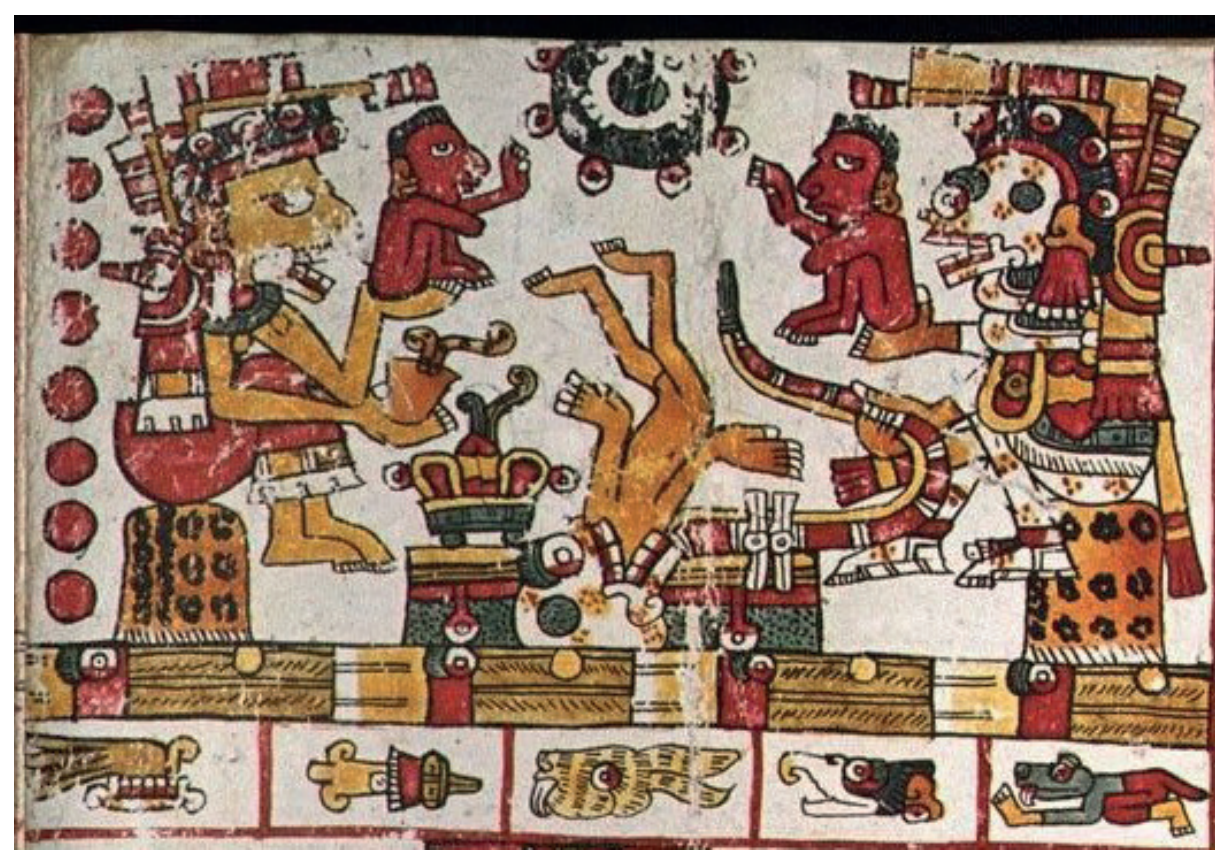

Fig. 6. Mictlantecuhtli y Mictecacihuatl, los dioses de Mictlan, y el motivo de la boca de la tierra, que está devorando al muerto, Códice Borgia 1963, p. 57.

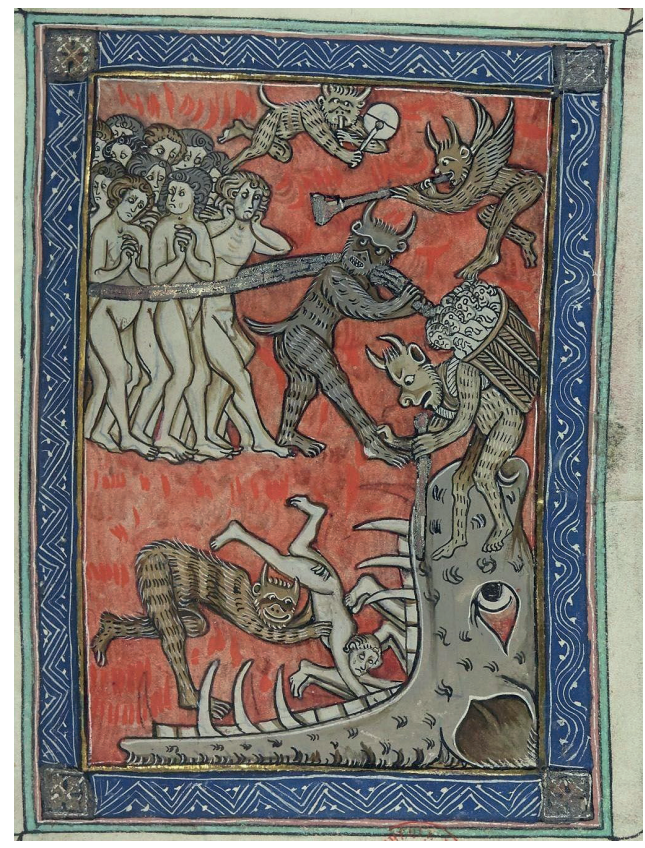

Fig. 7. La imagen de la boca del infierno, que está devorando a los pecadores, BnF, Français 13096, fol. 86r. 
Juan de Guzmán Itztlolinqui fue el gobernante de Coyoacan. Ejerció el poder desde 1526, cuando recibió el cargo de las manos de Hernán Cortés, hasta 1569 , cuando murió. ${ }^{21} \mathrm{Si}$ el canto analizado es efectivamente el mencionado por los Anales de Juan Bautista, es probable que Itztlolinqui era uno de los participantes activos de la celebración. También el sufijo diminutivo -ton agregado a su nombre parece situarlo simbólicamente entre los pipiltzinti, niñitos, es decir, los que entonan el canto.

En lo que toca al Presidente, según los traductores anteriores, era un título dado a Sebastián Ramírez de Fuenleal, el Presidente de la Segunda Audiencia de México en los años 1530-1535, ${ }^{22}$ quien logró fama de un gran defensor de los indígenas y apoyador del trabajo misionero. ${ }^{23}$ Después de la llegada del Virrey Antonio de Mendoza, Fuenleal volvió a España, donde vivió hasta su muerte en 1547. Al contrario de Itztlolinqui, Ramírez de Fuenleal está descrito por el canto como difunto, que va a ser enterrado. Entonces, ¿tal vez a él se refería el cantor con la metáfora del xiuhquechol por el que lloraba su corazón?

A esta interrupción temática que claramente parece indicar el contexto mortuorio de la entonación, siguen los versos dedicados a la narración interrumpida sobre el nacimiento de Jesucristo:

Ma calacoa in tipipiltzitzinti ye no cuel chocaz in topilauiltil yxhuetzcatocato maoc xoconahuilti a y xaltemocto macaoc xichoca ma mamama tinoteycatzin o anqui ye nicã an a.

A onca a belem ça ye motlacatili Jesu Christo ycelteotl y ye cemanahuac ontotonatoc $\hat{y}$ motlatlanextzi ye mitzonmotlatlautilia a yn Angeloti huile huile huiletzine.

Anca ye monãtzin ooo Santa Malia çan ca ye ipa ye tonmoyeyetztica y ye cihuapilli ye cemanahuac ontotonatoc y motlanextzi ye mitzonmotlatlauhtilia a yn Angeloti huile huile huile huiletzine.

Ca yohuall ixelihuia ye temoya o yn Spiritu Santo notiJesu Christo on ca oncan anaya y moxacal ymãca tonehcoya onilhuiço Ca moxxochintlapaltototl yn icelteotle ohua nomatzine y a.

Tla ticmahuiçoca tihuexotzinca pipiltzitzintine ticcahuane on ca oncan aya y moxacal ymanca Etc.

¡Que se haga la entrada de nosotros, los niñitos! Otra vez llorará nuestra alegría infantil, se va a sonreír. ¡Alegra al que desciende sobre la arena! No llores ya mi venerable hermano menor.

${ }^{21}$ GibSON 1960: 186.

22 Bierhorst 1985: 263; León-Portilla et al. 2011: 1207.

${ }^{23}$ RicARD 2014: 309. 
Allí en Belén ya nace Jesu Christo, el Dios Único. Ya el mundo ha resplandecido, se está relumbrando, te adoran los ángeles: huile huile huiletzine.

Ya estás con tu madre, Santa María, una mujer noble. Ya el mundo ha resplandecido, se está relumbrando, te adoran los ángeles: huile huile huiletzine.

La noche se partió, descendió el Espíritu Santo. Oh Jesucristo, estás allá, en tu casa de paja, es donde llegaste ¡oh Dios Único, oh Sobrino Mío!

¡Maravillémonos, nosotros los huexotzinca! ¡Oh, niños, oh hermanos menores! Estás allá, en tu casa de paja Etc. ${ }^{24}$

La noche horrorosa termina con el amanecer del Sol-Cristo. Los versos de arriba parecen una reelaboración artística en náhuatl de la profecía de Isaías: "El pueblo que andaba en tinieblas vio gran luz, los que moraban en tierra de sombra de muerte, luz resplandeció sobre ellos." ${ }^{25}$ Los motivos como: la casa de paja, los ángeles, María, la hora nocturna resplandecida por la luz divina, o el niño Jesús tumbado en la tierra o en la arena, estaban presentes en varias representaciones medievales de la Navidad y seguramente eran conocidos por los indígenas [fig. 8]. En consecuencia, los versos analizados podrían ser una descripción verbal de estas representaciones gráficas y/o teatrales, que seguramente formaban parte del programa artístico-evangelizador de los franciscanos.

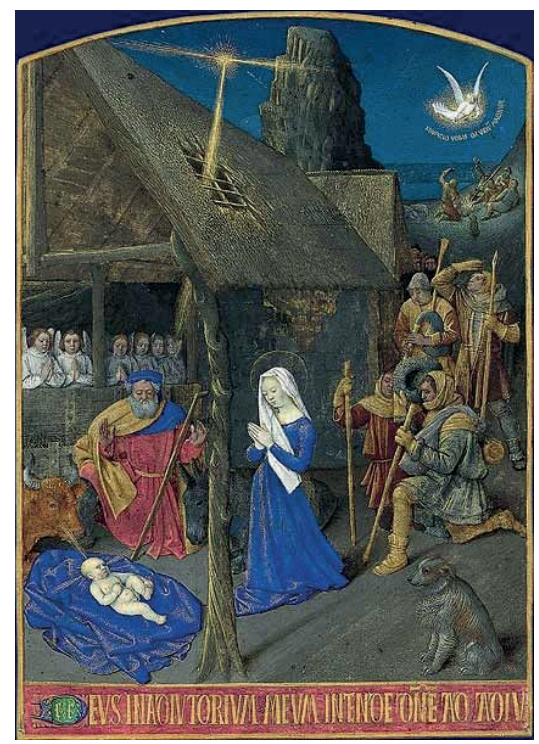

Fig. 8. Jean Fouquet, La Navidad según Hours de Étienne Chevalier, c. 1452.

${ }^{24}$ Cantares mexicanos 1994, fol. 46v, trad. de la Autora.

${ }^{25}$ La Biblia de las Américas 1997, Isaías 9:2. 
Por otro lado, cabe recordar que en la ideología indígena prehispánica el amanecer también simbolizaba un momento crucial en la historia del mundo, el inicio de una época nueva. ${ }^{26}$ De acuerdo con la memoria cultural de los mexica, fue precisamente al alba cuando sus ancestros salieron del lugar de origen, Chicomoztoc, o "Siete cuevas" [fig. 9]. La salida de la cueva al amanecer suponía, pues, sumersión en la luz de la vida nueva. Lo que es aún más significativo es que, de acuerdo con la relación de Domingo Chimalpahín ${ }^{27}$ [véase también: fig. 10], este acontecimiento fue anunciado por el canto de un pájaro. En este contexto, el hecho de que los ángeles del canto analizado no alaben a Dios con las palabras como Aleluya, Hosanna o Gloria, sino con huile huile, puede ser una referencia a aquel modelo prehispánico.

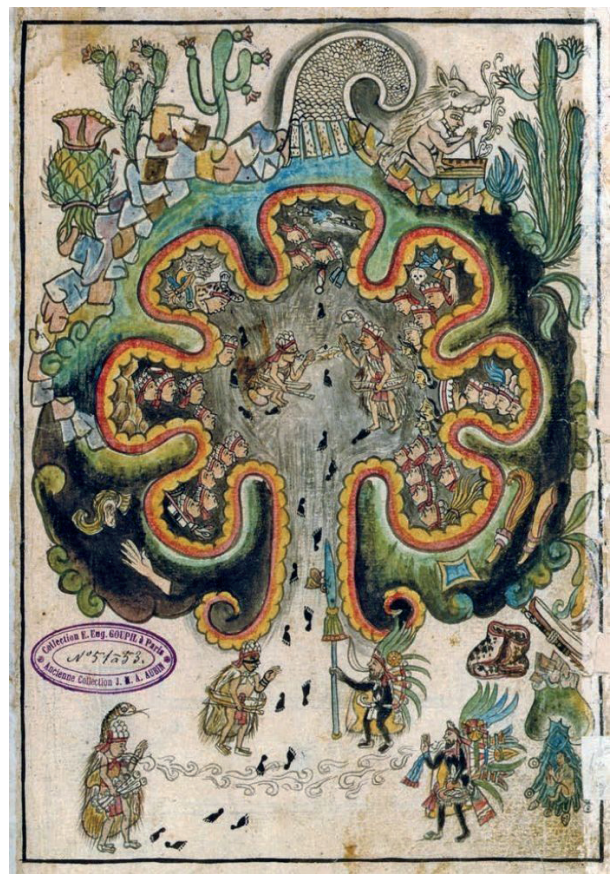

Fig. 9. Chicomoztoc - el lugar de origen de los aztecas, Historia tolteca-chichimeca 1947, f. $16 \mathrm{r}$.

26 Graulich 1990, 2002; López Austin 1998; Navarrete Linares 2011; Pepestraete 2008.

27 Chimalpahin Quauhtlehuanitzin 1998: 87-89. 


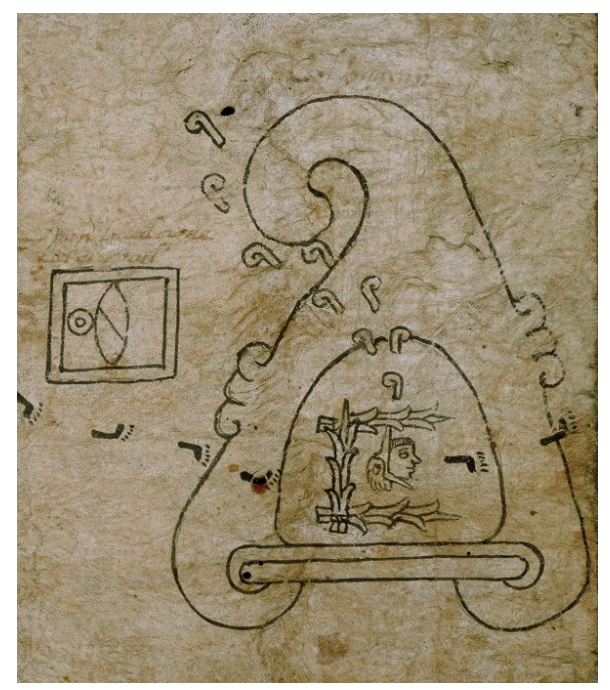

Fig. 10. Huitzilopochtli, o "Colibrí Zurdo", cantado dentro del cerro de Colhuacan y animando a los mexicas a iniciar su viaje hacia el sur, Tira de Peregrinación, p. 1.

En la siguiente parte del canto vuelve el tema de la muerte y de las exequias:

Cototiqui titiqui titoti titoti cototiqui titiqui titoti cototo cototo cototo coto

Ma xonpactaca tomachhuane anpipiltzitzinti maca ximochoquillittacan oo tlaça tlaça xontlatlayocolcuicataca ayao ohuayaye ça ye ic nichocã tinotlatlatzin yye y aco tle tontlaquetz in y çan ca iuhqui toyazque can ompa ximohua çan tipipiltzitzinti yao ohuayaye.

$\hat{Y}$ tlapalomixochitl y ye xochitl tlatlatzcatimania çan tiquicecenquixtia oo a yca titapana çan tipipiltzitzinti o xiuhquecholceceliztoc ohua aye.

¡Alegráos, oh sobrinos míos, vosotros los niñitos! ¡No lloréis, id a cantar la tristeza! Así lloro. Eres mi tío, ¿qué consejos tienes? ¿Así que nosotros los niñitos nos iremos allá donde se descarna a la gente? Se tienden chispeando las flores de hueso coloradas, las flores de sahumerio, escoges entre ellas. Nos ceñimos con mantas, nosotros los niñitos. El ave tlauhquechol está brotando. ${ }^{28}$

El fragmento empieza con la llamada al canto y expresión de la ansiedad ante la suerte humana en el más allá desconocido: “¿Así que nos iremos allá donde se descarna a la gente?" En la frase siguiente aparece un difrasismo ${ }^{29}$

${ }^{28}$ Cantares mexicanos 1994, fol. 46v, trad.de la Autora.

29 Para la definición y el estudio pormenorizado de este recurso retórico, véase, entre otros: Garibay 1971:65; Montes de Oca 2000; Dehouve 2009. 
florido: in tlapalomixochitl in yexochitl, "la flor de hueso colorada, la flor de sahumerio", cuyos significados metafóricos revelan otros elementos del mestizaje cultural presente en este canto.

Como observa Louise Burkhart, si bien la imaginería del más allá florido de los nahuas era una de las aprovechadas por los frailes con más entusiasmo para describir el Cielo, estos no estaban conscientes del verdadero significado y papel desempeñado por ella. La autora explica que aprovechamiento de flores y pájaros en los discursos rituales nahuas no servía solo para hacer una descripción artística de algún lugar lejano e invisible, sino que era un acto de transformar la realidad presente en un espacio sagrado, donde lo divino y lo humano podían entrar en contacto. ${ }^{30}$ Además, según Burkhart la flor tlapalomixochitl, con su color rojo y forma de una llama, en algunos contextos -como el analizado por la autora "Canto de Pentecostés" registrado en la Psalmodia cristiana de fray Bernardino de Sahagún- podía ser una metáfora del fuego ${ }^{31}$ Yuxtapuesta al yexochitl, "flor de sahumerio" forma pues el difrasismo cuyo significado sería "fuego". Esto se ve aún más claro si se toma en cuenta el verbo, que denota la acción llevada a cabo por dichas flores. Tlatlatzcaliztli en el diccionario de Alonso de Molina está traducido como: "estruendo o sonido de palos quebrados, o de trompetas, o ruido de hoguera grande." ${ }^{32}$ Quiero proponer aquí a modo de hipótesis, que la expresión $\hat{Y}$ tlapalomixochitl y ye xochitl tlatlatzcatimania, "se tienden chispeando las flores de hueso coloradas, las flores de sahumerio" podía referirse a la incineración o sahumerio del bulto morutorio simbólico de Ramírez de Fuenleal, quien en este fragmento sería representado otra vez como el ave xiuhquechol. Por otro lado, el verbo tlatlatzca aparece en varios contextos como asociado en un difrasismo con el verbo сиесиероnia, que podríamos traducir como "explotar floreciendo". ${ }^{33}$ La expresión entera sirve para describir el vigor y la abundancia de la vida vegetal que está renaciendo, lo que en realidad corresponde con los significados del verbo celiya, "brotar", que en el fragmento discutido describe al ave xiuhquechol. Resumiendo, el significado general connotado por los símbolos empleados en estos versos sería el de "renovar la vida a través del fuego", una idea muy presente en la cultura nahua con su concepto de la vida y muerte como fuertemente unidas y complementarias, y ritos de exequias basados en la incineración [fig.11].

\footnotetext{
30 BurkHART 1992: 89.

31 BuRKHART 1992: 95.

32 Molina 1992, II: 139v.

33 SAHAGÚn 19501982, XI: 198, 202, 211, 283.
} 


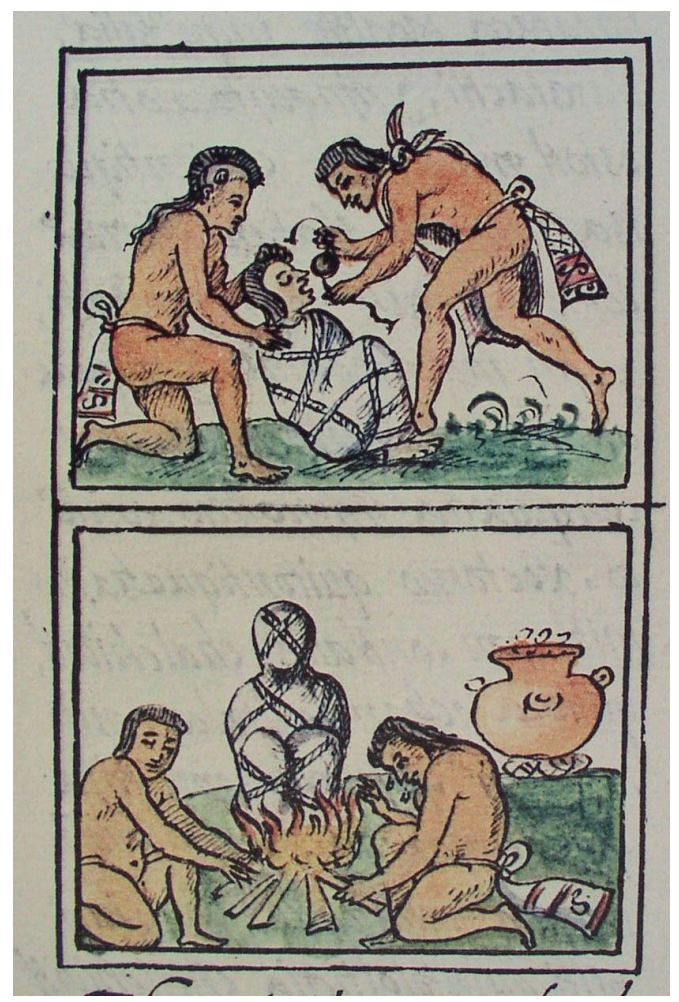

Fig. 11. Las exequias mexicas, SAHAGúN 1950-1982, III.

No obstante, vale la pena recordar que también en la cosmovisión cristiana está presente la idea de que los que quieran pasar a la vida mejor en el Cielo tienen que llegar purificados por el fuego: "Si la obra de alguno es consumida por el fuego, sufrirá pérdida; sin embargo, él será salvo, aunque así como por fuego" dice San Pablo en su Primera carta a los corintios. ${ }^{34}$

Ma xihuallacan ticcahuane $\hat{y}$ man toconteocuitlaamatlayehuaca yn topapalomatl ic tellel onquiçaz ohuao aye. $\hat{Y}$ çan totlayocol ypan toncacate $\hat{y}$ pipiltzitzinti quê toconchihuazque e $\hat{y}$ ma huel tiquehua yectli a ycuic Dios a y yoyahue yao aye. Ma xihualhuian tocnihuane a in mã tonahuiaca ayahueye aço huel toconpoa toconehua oo yectli ya ycuic Dios ha yyoyahue yao aye.

¡Venid, oh hermanos nuestros, levantemos los papeles dorados, nuestros papeles mariposas, con ellos nuestra tristeza acabará. En tristeza estamos, nosotros los niñitos. ¿Qué haremos? ¡Levantemos los buenos

${ }^{34}$ La Biblia de las Américas 1997, 1 Corintios 3:15. 
cantos de Dios! ¡Venid, oh amigos nuestros, alegrémonos! Por ventura leemos, cantamos los buenos cantos de Dios. ${ }^{35}$

De acuerdo con la información proporcionada por los informantes de fray Bernardino de Sahagún, una de las preparaciones del cuerpo antes de incineración era la elaboración de las vestimentas de papel por los ancianos instruídos en esa tarea. ${ }^{36}$ Entonces, "los papeles dorados, nuestros papeles mariposas" podrían referirse a esos adornos de papel, que en los tiempos prehispánicos acompañaban a los muertos al más allá. Otra posibilidad es que se trate de las hojas con inscripciones pictográficas de los "buenos cantos de Dios", que van a ser entonados para aliviar la tristeza de los presentes. Los libros en formato europeo, porque esa era la forma tenían los catecismos preparados por los frailes [fig. 12], efectivamente, se parecían a las mariposas con alas de muchos colores y en ellas se encontraban los cantos preciosos, dorados.

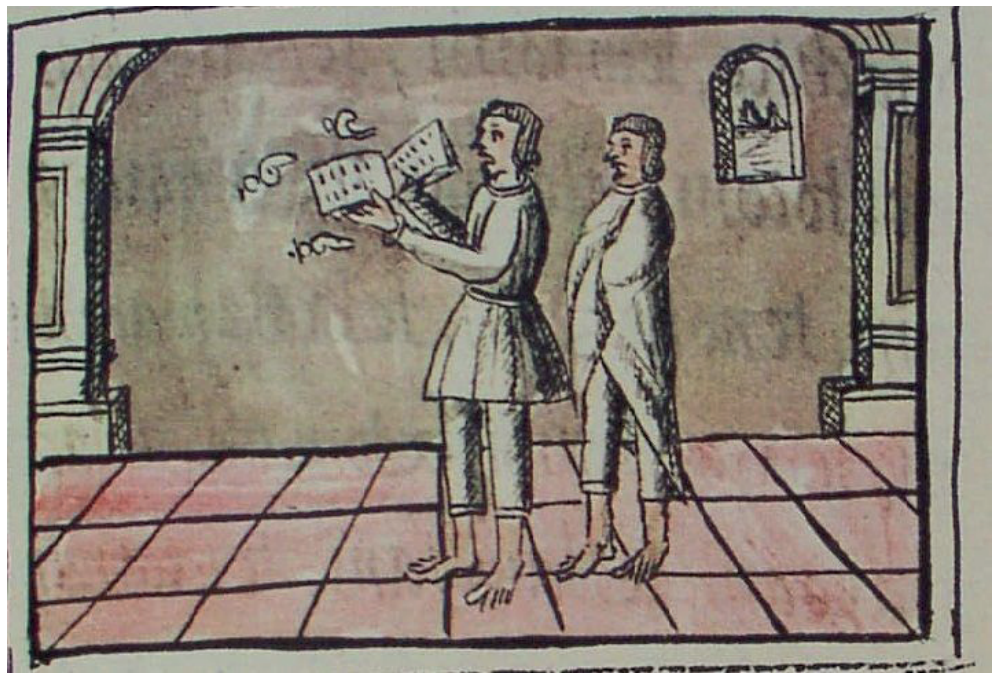

Fig. 12. Los jóvenes indígenas educados en el convento entonando cantos a partir de los libros en formato europeo, SAHAGún 1950-1982, Libro X.

La siguiente parte del canto empieza con la evocación del patrono del convento, San Francisco:

Cototico toticoto tiquiti cototiquiti cototiquiti

$\hat{Y}$ mã ticuicayelcicihuicany tiMexicapipiltzitzintini ye axcã motlecahui O ye totatzin.S. Palacizco yehuaya ilhuicac ytec ho ohuili ayea. $\hat{Y}$ ma

${ }^{35}$ Cantares mexicanos 1994, fol. 47r, trad. de la Autora.

36 SAHAGÚN 1950-1982, III: 40. 
ypampan tonchoquizcuicuiycaca tonahahuiaca xochitecpã calteca ya yecoya tlali icelteotl yehuaya ylhuicatl ytec ho ohuili ayea. O a mach ya nel tomachhua man tlatlauhtiloya $\hat{y}$ ca çanio in teotl Jesu Christo $\hat{y}$ ca tipilhua an titlachihualhua y ma ic xonahahuiacã teteucti tomachhuane. Hualchocã toyollo tihuexotzinca conetzitzinte ye in tipipiltzitzinti a anqui tomacehual amoxihcuiliuhqui ya ytlatol Jesu Cristo $\hat{y}$ Ca tipilhuan titlachihualhuã y Etc. O anca iuhquin quetzallin tonhuitoliuhtoque o yn tipipiltzitzinti yc tõtopechteca yc tocontlatlauhtia ao yn $S^{\text {ta }}$ malia in mochipa ichopchtli yez ayancayancaya. $\hat{Y}$ nepapan yhuian tlatlapalpouhtoque in toncozcaçotoque ic tontopechteca yc tocontlatlauhtia oa in $S^{\mathrm{ta}} \mathrm{Ma}$ lia $\hat{y}$ mochipa ichpochtli..

Suspiremos los cantos, nosotros los niñitos mexicas, hoy ha subido al cielo nuestro padre, San Francisco, en el cielo está ¡ho ohuili ayea! Por lo tanto cantemos llorando en el palacio florido, en casa. El Dios Único ya ha llegado a la tierra de su lugar de permanencia, del Cielo. Es necesario, oh sobrinos nuestros, que sea rogado el único Dios, Jesucristo, porque somos sus hijos, somos sus criaturas. Con eso alegráos señores, sobrinos nuestros. Viene llorando nuestro corazón, somos huexotzincas pequeños, somos niñitos. De esa manera nuestro merecimiento está escrito en el libro de la palabra de Jesucristo. Somos sus hijos, somos sus criaturas. Etc. Como la pluma preciosa nos inclinamos, nosostros los niñitos, nos humillamos, le rogamos a Santa María, que siempre Virgen será. Sosegadamente se colorearon de diversos colores, se ensartaron (las cuentas de rezar). Nos humillamos le rogamos a Santa María, que siempre Virgen será. ${ }^{37}$

Este fragmento casi no contiene elementos propiamente indígenas, es una traducción de la realidad cristiana al náhuatl. El único elemento digno de mencionar aquí es tal vez el xochitecpan, "palacio florido". Si bien es cierto que el término en cuestión puede referirse a las decoraciones floridas preparadas para la celebración, no se puede olvidar que la costumbre de organizar un espacio florido para el ritual estaba muy arraigada también en la religión mexica precolonial y, como ya se ha mencionado, servía para reestablecer el espacio sagrado del mito, posibilitando el contacto directo entre el mundo divino y humano. ${ }^{38}$ Este contacto lo parecen buscar las voces del canto en los versos que siguen a la cadencia del tambor. Echando mano de la estética prehispánica los cantores expresan el deseo de convertirse en las aves preciosas, dignas de acceder a la gloria del paraíso:

Tihuexotzinca netle tipipiltzitzinti $\hat{y}$ tlaoc ya tehuãti toconcuicaxochicuentaxpoaca yectli yan cuicatl y man tiquetzalçaquaxiuhquechol-

37 Cantares mexicanos 1994, fol. 47r, trad. de la Autora.

${ }^{38}$ Hill 1987; Burkhart 1992. 
huihuicomacani yn ixpã dios nocnihue Ma netotiloya. A onquetzalamoxihcuiliuhticac ontlatla' machnenepaniuhtoc motlatol Jesu Cristo $n$ aya man tiquetzalçaquaxiuhquecholhuihuicomacani Etc.

Tlaatlapalilpitoqui tlayolcopixauhtoc $\hat{y}$ motlatol a amoxcalitec $\hat{y}$ dios aya oncã mitznonotza mitzoyatlatlauhtia in Patilime ye topampã timomacehualhuan a. Ahua y ahua conetle huexotzinca anpipiltzitzinti aco ye quinexti yectli nemilizçotl ahua o aye o anqui ya yehuatl totatzin.S. Palacizco icnoyotica mone'nemiticon tlalticpac ye nicã yuh nêca yn tt ${ }^{\circ}$ Jesu Cristo .n.a.

Somos huexotzinca, somos niñitos. Recemos, cantemos el Rosario, los buenos cantos. Como las aves: quetzal, zacuan y xiuhquechol seamos llevados ante la cara de Dios. ¡Amigo mío, que se haga el baile! ¡En el libro precioso están escritas, se reparten, se entrecruzan tus palabras, oh Jesucristo! Como las aves: quetzal, zacuan y xiuhquechol seamos llevados Etc.

Ató varios colores, en el corazón se esparció tu palabra. Allá, dentro de la casa de libros, los padres te llaman, te ruegan, oh Dios, por nosotros que somos tus sirvientes. ¡Oh ciudadanos, niños, huexotzincas, sois niñitos! En lo alto se presentó la santa historia: Nuestro padre, San Francisco, en miseria moró en la tierra, vivió aquí como nuestro señor Jesucristo. ${ }^{39}$

Las aves quetzal, zacuan y xiuhquechol son especies que se repiten a lo largo de todo el manuscrito de Cantares mexicanos y, por lo general, evocan a los guerreros valientes y heroes culturales de la tradición oral náhuatl. Para los frailes, en cambio, los seres alados que permamentemente podían disfrutar de la presencia divina eran los santos y los ángeles. Por ejemplo, en la imagen titulada "La Madonna de la Rosaleda" atribuida a Michelino da Besozzo o Stefano da Verona, se presenta a la Virgen María con el Niño Jesús sentada en medio de la rosaleda, rodeada de las flores, aves y ángeles [fig. 13].

Por otro lado, hay que recordar que también San Francisco estaba relacionado con el mundo de la avifauna gracias a su famoso "Sermón a las aves" narrado en la Leyenda mayor de Buenaventura de Bagnoregio, que a su vez inspiró varias obras gráficas de la época [Fig. 14]. ${ }^{40}$

39 Cantares mexicanos 1994, fols. 47r-47v, trad. de la Autora.

40 Guerra 1998. 


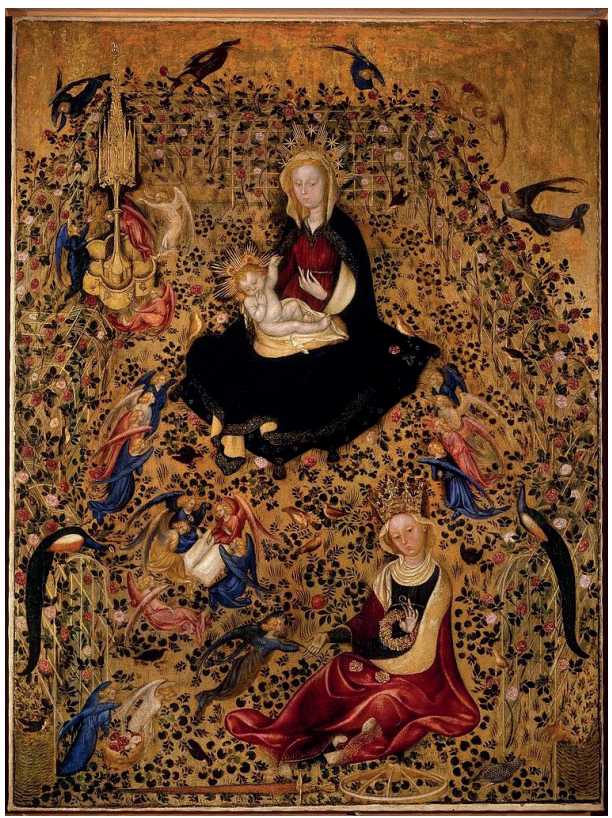

Fig. 13. La Madonna de la Rosaleda, atribuida a Michelino da Besozzo o Stefano da Verona, siglo XV.

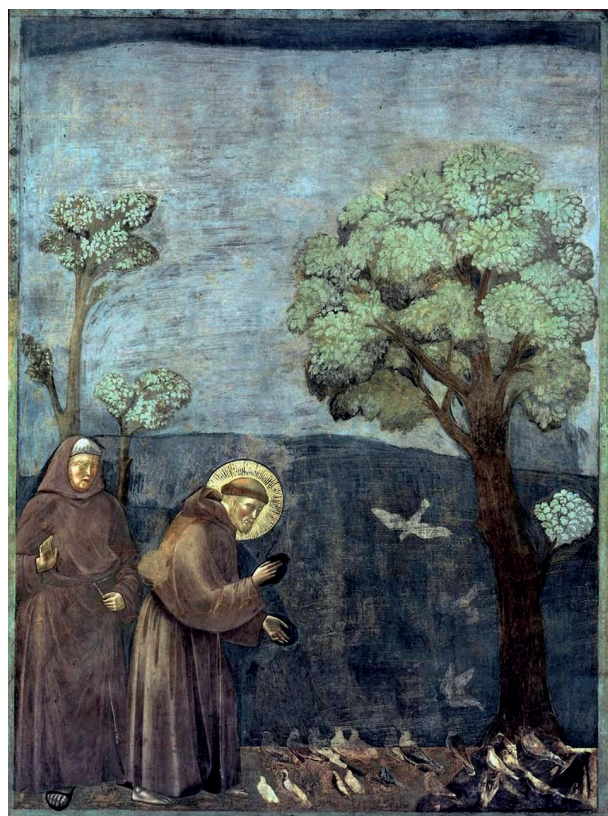

Fig. 14. Giotto di Bondone, San Francisco predicando a los pájaros, 1280-1283, Basílica de San Francisco de Asís, Italia. 
Finalmente el mismo Francisco también aparece a veces como un ser alado, relacionado con uno de los ángeles de Apocalipsis. ${ }^{41}$

En este momento, termina el enfoque en el santo y la atención se presta otra vez al Presidente Sebastián Ramírez de Fuenleal, quien también cobra rasgos de pájaro:

Timoquetzalyyectia toncuiya teixpã timoquetzaya amoxtli mahtlapal an ticçocohuaya tixiuhcoyolinpapalotl y ya pelesitente çan toncuicatinemin tlacuilolapani çan timotzetzeloaya tlapalcamopalcamilcecelia moyool yyãcaya yectliya mocuic yectliya moxochiya toztlapalhuiconticac ytlan tõnenemi tonquiquiztinemi quetzalacaxochiatitla tôtlatlahtoayan tlapalcamopalcamil Etc. A o xoxopan on tinemi tlalliya ycpac tomachvan ticcahuane man tocõtetequica ca camopalcaxtlatlapaxoxoochitlaya can cuel achic õnenenecoya. A yhuan ommomalin cuepontimani ya tolciymaxochitl mã tocontetequica ca camopalcaxtlatlapa.

Te mejoras las plumas, cantas ante la gente, te levantas, como el libro de pinturas extiendes tus alas, eres la mariposa de color turquesa, joh Presidente! Cantando vives en el agua de pinturas. Te sacudes, tu corazón brota con colores: rojo, morado y bronce. Buenos son tus cantos, buenas son tus flores. Con amarillo y rojo estás, vives a su lado. Emerges entre las aguas floridas de cañas preciosas, es el lugar donde hablas. Con rojo, morado y bronce... ${ }^{42}$

El Presidente está presentado aquí como uno de los habitantes alados del paraíso florido: se mejora las plumas como un pájaro, extiende sus alas como mariposa de turquesa. Podría parecer una asimilación perfecta de la estética prehispánica a las ideas del cristianismo. No obstante, las frases que siguen revelan varios rastros de las antiguas creaciones, que se entonaban en honor a los guerreros muertos y que muy difícilmente se justificarían en un canto puramente cristiano.

Para empezar, todas las metáforas relacionadas con el agua -cantar en el agua de pinturas, emerger entre las aguas floridas de cañas preciosas- evocan el Este y la costa del mar, que en la ideología nahua funcionaba como el lugar del paso al más allá, a la Casa del Sol. De acuerdo con el mito azteca sobre la creación de la música, el mensajero divino, Yohualli Ehecatl, fue enviado a la Casa del Sol y en su camino tuvo que atravesar el mar del Este. Solo gracias a la ayuda de los seres marinos, que lo llevaron a cuestas al otro lado, logró cumplir con su tarea.$^{43}$ La costa del océano fue también el destino del viaje terrestre del mítico gobernante-héroe tolteca, Quetzalcoatl, quien al verse obligado a abandonar

\footnotetext{
${ }^{41}$ LARA 2016.

${ }^{42}$ Cantares mexicanos 1994, fol. 47v, trad. de la Autora.

${ }^{43}$ Histoyre du Mexique 2005: 111-112; Mendieta 1999.
} 
su ciudad se dirigió hacia el Este. En la costa se despidió de sus compañeros y se sumergió en las aguas del mar. De este modo terminó su vida humana y se transformó en la Estrella Venus. ${ }^{44}$

Por otro lado "La mariposa de color turquesa" en el lenguaje simbólico de los nahuas sería la metáfora del fuego, tanto por su color, como por su forma.

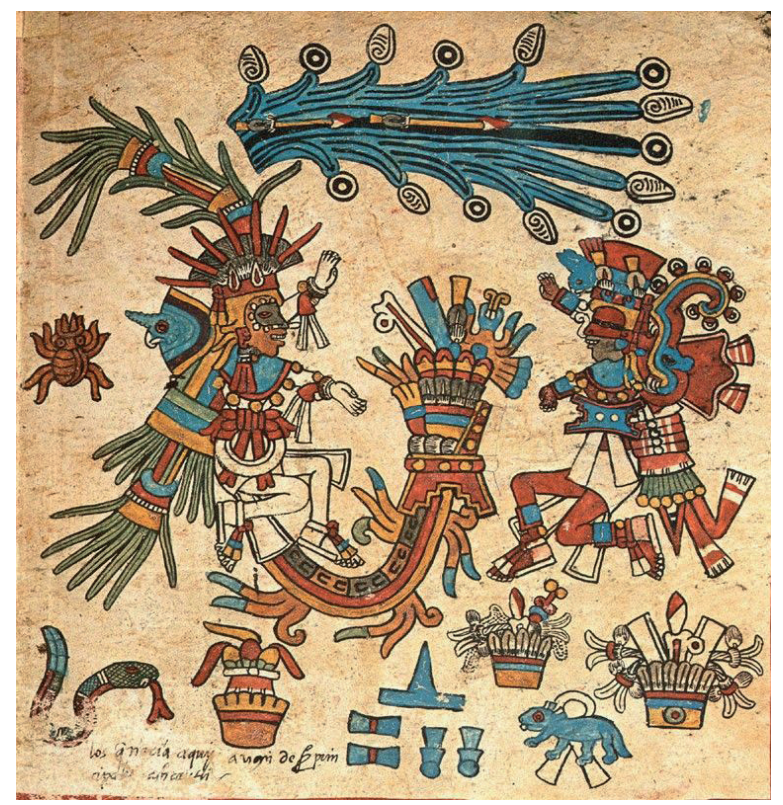

Fig. 15. Xiuhtecuhtli y Venus, Códice Borbónico 1980, lam. 9.

En la lámina 9 del Códice Borbónico [fig. 15] están representados: Xiuhtecuhtli - el dios del fuego (a la izquierda) y Tlahuizcalpantecuhtli - Venus (a la derecha). La mariposa de color naranja-turquesa que sale de la vasija situada sobre el trono que se encuentra entre los personajes simboliza el fuego. Además, alrededor están otros objetos de color turquesa, que en la ideología nahua era también el color de la nobleza. ${ }^{45}$ Otra representación del fuego en forma de mariposas estilizadas está visible en la imagen de la incineración del bulto mortuorio en el Códice Tudela, o sea precisamente en el contexto de las exequias [fig. 16].

\footnotetext{
${ }^{44}$ Anales de Cuauhtitlan 1992.

45 Anders, JANSEN y Reyes García 1991: 144-146; le agradezco también a Katarzyna Mikulska por llamar mi atención sobre la relación entre la mariposa y el fuego en las fuentes gráficas.
} 


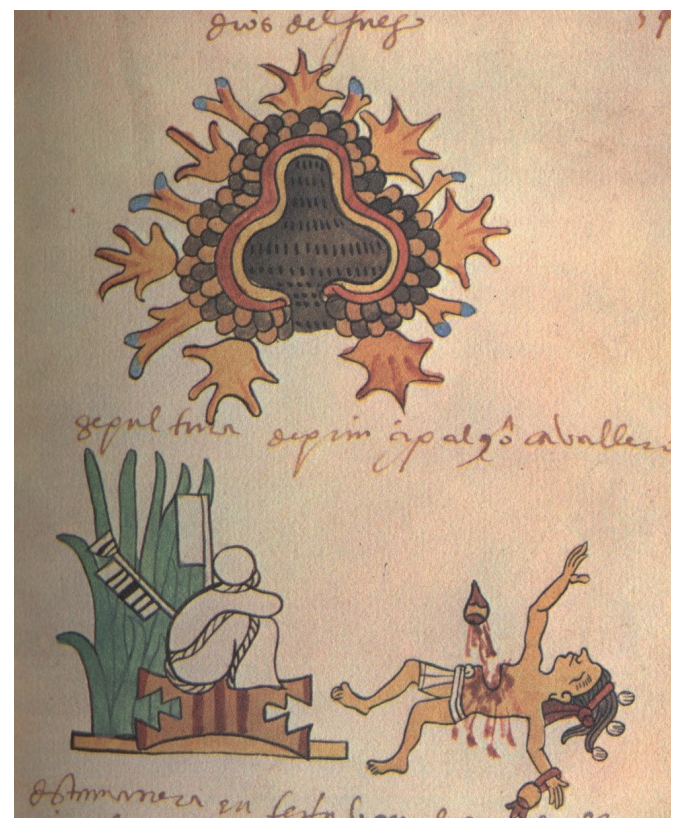

Fig. 16. Rituales mortuorios, Códice Tudela 2002, f. 57r.

Entrar en el agua o atravesarla, como en el caso del río de Mictlan, era una metáfora nahua para referirse a la muerte y la transformación relacionada con ella. En el Este se encontraba además la llanura donde los guerreros fallecidos en el campo de batalla o en la piedra del sacrificio esperaban el amanecer para acompañar al Sol en su trayecto hacia cenit. El Presidente del canto analizado es, en mi opinión, comparado con uno de esos soldados valerosos, lo que indican las palabras: "Te sacudes, tu corazón brota con colores: rojo, morado y bronce", es decir, los colores que puede tener la sangre.

Estos colores predominan también en los versos que siguen, esta vez expresando la fugacidad de la vida humana, comparada aquí a la flor:

A o xoxopan on tinemi tlalliya ycpac tomachvan ticcahuane man tocõtetequica ca camopalcaxtlatlapaxoxoochitlaya can cuel achic õnenenecoya. A yhuan ommomalin cuepontimani ya tolciymaxochitl mã tocontetequica ca camopalcaxtlatlapa.

¡Entre la verdura vivimos en la tierra, oh sobrinos nuestros, oh hermanos menores nuestros! Cortemos flores variadas: moradas, ocres, rojas, que sólo por muy breve tiempo son deseadas. Se tuercen, están brotando las flores de tulares. Cortemos flores variadas: moradas, ocres, rojas... ${ }^{46}$

${ }^{46}$ Cantares mexicanos 1994 , fol. $47 \mathrm{v}$, trad. de la Autora. 
Aunque la comparación de la vida humana con la naturaleza que cíclicamente muere y se renueva no es exclusiva de las culturas indígenas de México, las ideas acerca del modo más deseado de morir presentadas en este fragmento están muy arraigadas en la cultura nahua prehispánica. Como observa Patrick Johansson en su trabajo acerca de los ritos funerarios mexicas, la muerte ideal para un hombre nahua era la muerte joven, cuando el cuerpo todavía estaba en el auge de su condición física y psíquica ${ }^{47}$ Por esa razón, las voces del canto animan al público a cortar flores en el tiempo de verdura, cuando están en su pleno florecimiento, porque solo entonces "por muy breve tiempo son deseadas". Al mismo tiempo, las flores que se tuercen pueden evocar metafóricamente el campo de batalla, donde los cuerpos de guerreros se entrecruzan, se doblan, se lesionan cubriéndose con colores del xochiatl, "el agua preciosa, florida", la sangre: moradas, ocres, rojas. ${ }^{48}$

Los atributos del guerrero caracterizan a Ramírez de Fuenleal también en los primeros versos de la secuencia que sigue:

Coto coto tiqui tocoti coto coti quito coti cotocoto coto coto quitiquitiquitiquiti

$\hat{Y}$ mocoyoltzin mocoyoltzin mocoyoltecuecuex ontzitzilintoc ye cemanahuac Pelesitente ma xahuiyao xahuiyaoo yao ayahue. Y ma quihuitequican ŷteponaz pipiltzitzintin xonmihtoti xonmitoti Etc.

¡Tus cascabeles, tus cascabeles, tus brazaletes de cascabeles están resonando en todo el mundo, oh Presidente! ¿Que los niños toquen sus atabales! ¡Baila! ¡Baila! ${ }^{49}$

Los cascabeles llamados en náhuatl coyolli y oyohualli, eran producidos de materiales diversos, como oro, cobre o barro y se utilizaban como uno de los atributos de los guerreros que se presentaban en el campo de la batalla [fig.17].

Su papel excedía el de un simple adorno: en la descripción de la guerra entre las tropas mexicas de Motecuhzoma Ilhuicamina y los ejércitos huaxtecos, los cascabeles llevados por esos últimos claramente funcionaban como un tipo de arma cuyo objetivo era distraer al enemigo:

Los huastecos arremetieron a ellos con un ruido de cascabeles de palo que traían por la orla de las corazas y otros, con cascabeles de metal grandes, que traían a las espaldas y a los pies, con los cuales hacían un ruido extraño..$^{50}$

\footnotetext{
47 JOHANSSON 2016.

48 BiERHorst 1985.

49 Cantares mexicanos 1994, fol. 47v, trad. de la Autora.

${ }^{50}$ DuRÁn 1967, II: 167.
} 


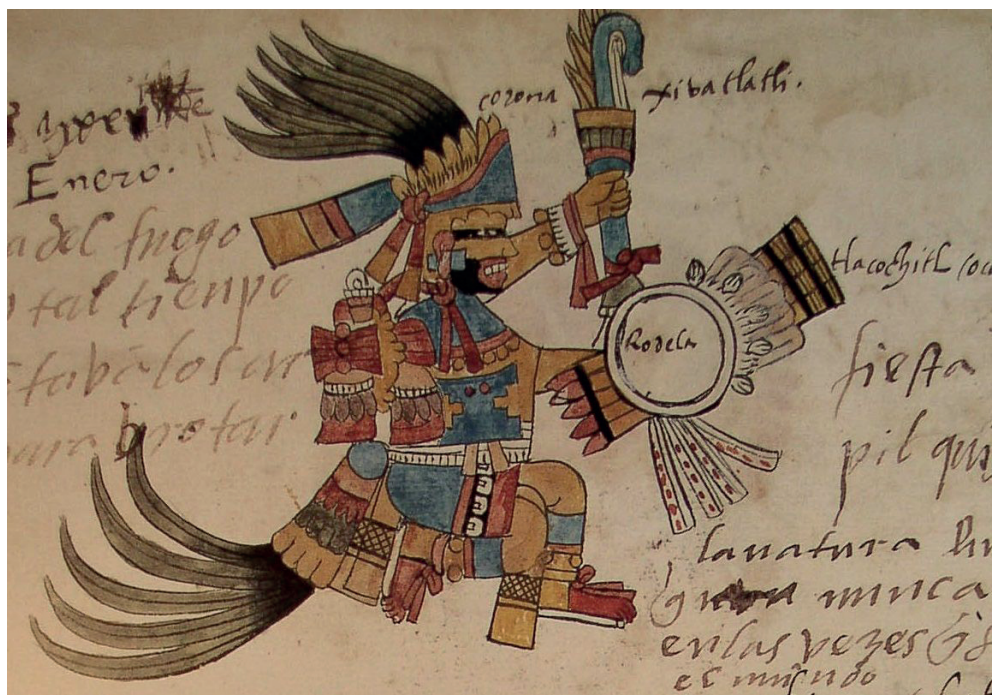

Fig. 17. Xiuhtecuhtli con los cascabeles de oro en los tobillos, Códice Telleriano-Remensis 1995, fol. $6 \mathrm{v}$.

Según Arnd Adje Both, ${ }^{51}$ en la cultura nahua una importancia especial se daba a los cascabeles hechos de metales ya que los sonidos metálicos producidos por ellos eran considerados expresión del poder señorial, por lo cual su uso estaba restringido a los personificadores de los dioses y los representantes de la alta nobleza. ${ }^{52}$ De este modo, la descripción de Ramírez de Fuenleal como poseedor de los cascabeles cuyo sonido se extiende en todo el mundo es compararlo con uno de esos elegidos del Sol, guerreros valerosos o personificadores divinos sacrificados, que con sus armas hacían un alboroto grande al amanecer para darle la bienvenida al astro.

Los versos que siguen presentan varias referencias a los personajes y acontecimientos históricos concretos, que abren varias posibilidades de contextualización del canto analizado:

Çan nixochintlatlayocoya nihuexotzincatl ye nipiltzintli ye nitztlolinqui noconelnamiqui ce totzi oncã ye poliuhatlyaytec ylhuicaapã xitlaneltocaca ahuatomachvane. $\hat{Y}$ çan no iuh ye quichiuh Nozcacauhtzin oo apa hualhuetz ye tenochtitlani ymatiya ye yehua Malques xitlaneltocaca ahua.

${ }^{51}$ Вотн 2008: 32.

52 Véase por ejemplo las descripciones de los personificadores de las divinidades en las fiestas comentadas en el Códice Florentino (SAHAGúN 1950-1982, Libro II: 69, 92, 93). 
Sólo compongo flores, soy de Huexotzinco, soy niño Itztlolinqui. Yo recuerdo a Cetochtzin, allá en el agua, en el mar desapareció, ¡creedlo sobrinos nuestros! Del mismo modo lo hizo mi venerado padre, cuando el agua vino a caer sobre Tenochtitlan. Fue avisado el Marqués, creedlo. ${ }^{53}$

El modelo retórico de este fragmento otra vez es muy parecido al de los cantos de temas prehispánicos dedicados a la conmemoración de los señores muertos. Los dos nobles evocados por la voz de Itztlolinqui son su hermano mayor Cetochtzin y su padre Quauhpopoca. De acuerdo con la información proporcionada por Fernando de Alva Ixtlilxochitl, en 1519 Quauhpopoca fue acusado por Cortés de haber matado a cuatro españoles, por lo cual junto con su hijo mayor fueron condenados a muerte y públicamente quemados. ${ }^{54} \mathrm{El}$ gobierno en Coyoacan tomó entonces otro de los hijos de Quauhpopoca, don Hernando Cetochtzin, quien murió en 1525 en Hueymollan, durante el viaje de Cortés a Honduras. ${ }^{55}$ Tomando en cuenta que era un viaje en el cual perdieron vida los principales gobernantes indígenas acusados por los españoles de conspiración contra la Corona, entre ellos Cuauhtemoc de Tenochtitlan, Tetlepanquetzatzin de Tlacopan y Cohuanacochtzin de Texcoco, es muy probable que la muerte de Cetochtzin tampoco fue accidental. ${ }^{56}$ Tal vez a ello se refieren las últimas palabras de este fragmento: "Fue avisado el Marqués, creedlo."

Vale la pena subrayar el modo metafórico de representar la muerte de los dos como la entrada en el agua del mar. Por la relación de Chimalpahin sabemos que los supuestos traidores fueron ahorcados, pero el cantor dice de $\mathrm{Ce}$ tochtzin que "allá en el agua, en el mar desapareció". Aún más signifitivas son las palabras que se refieren a la muerte de Quauhpopocatzin, el padre de Itztlolinqui. El también se sumerge en el agua, fallece durante la ola de la conquista española que trae la muerte a la civilización antigua del Valle de México: "Del mismo modo lo hizo mi venerado padre, cuando el agua vino a caer sobre Tenochtitlan." La pregunta que podría plantearse aquí es si esta conmemoración de los supuestos traidores nahuas era visible para los españoles que asistían al espectáculo. También vale la pena preguntarse ¿qué significados conllevaba para los indígenas? ¿Era un mensaje político ajustado a los intereses de la administración española que decía tanto como "Recordad como terminaron los que se intentaron rebelar"? ¿O era más bien la iniciativa indígena de eternizar a los antiguos gobernantes, alzados a sus cargos todavía en los tiempos de la libertad; un intento de mantener la identidad propia y guardar las tradiciones antiguas veladas en un canto entonado bajo el control español?

\footnotetext{
${ }^{53}$ Cantares mexicanos 1994, fol. 47v., trad. de la Autora.

${ }^{54}$ Alva IxtLilxochitl 2000: 279

55 Codex Chimalpahin 1997: 149

56 Chimalpahin Quauhtlehuanitzin 1998: 169; MadajCZaK 2006: 76-77.
} 
El contexto parece indicar a que con esas palabras se evocan los antepasados felices que precedieron al Presidente en su camino al más allá. Gracias a la creación por medio del canto de un espacio florido donde se podía entablar el contacto entre lo humano y lo sobrenatural, los que ya estaban gozando de la gloria eterna, sea la de la Casa del Sol o la del Paraíso Cristiano, podían venir a recibir a su compañero nuevo. Y, efectivamente, así se presentan los siguientes dos nobles indígenas, que se mencionan en esta parte del canto:

Xiquincaquican y ximotacany an teteuctini ça ye huitze huitze, mittotitihuitze a in pipiltzitzinti acolihuaca yehua yoyonton i tlacopã ton Capilel in xiuhcoyolla a ihcahuaca amoteecuecueyotzin ayeo. ho aya yeha.

¡Ó́dlos, mirádlos, señores! Ya vienen, vienen, vienen bailando los niñitos: Yoyontzin pequeño de Acolhuacan, don Gabriel de Tlacopan. Los cascabeles de turquesa están resonando, son vuestros pendientes brillantes ayeo. ho aya yeha. ${ }^{57}$

De acuerdo con las informaciones proporcionadas por los colaboradores de Sahagún, Yoyontzin era el gobernante de Texcoco después de la muerte de Ixtlilxochitl, pero reinó solamente un año. ${ }^{58}$ Como reporta Chimalpahín, murió poco después de la coronación por causa de una de varias epidemias, que atravesaron el Nuevo Mundo alrededor de 1531. Otro de los que vienen a recibir al muerto es don Gabriel, identificado por Bierhorst como Don Gabriel Tegpal, que tomó el trono de Tlacopan después de la muerte de Tetlepanquetzanitzin en $1525 / 26$, pero ya en 1528 fue llevado por Cortés a España y nunca volvió. ${ }^{59}$ Aunque no tenemos informaciones acerca de su muerte, el hecho de que haya desaparecido por causa de los españoles, y además, en efecto de cruzar, literalmente, las aguas del océano, permite calificar a don Gabriel, como otro de los moradores felices del más allá florido.

Después de los gobernantes de Texcoco y Tlacopan, es decir de dos de las tres ciudades que formaban la Triple Alianza, aparecen los personajes relacionados con la ciudad más importante, Tenochtitlan:

$\hat{Y}$ ma xonmittoti ma mellel onquiça tla yaa ontzitzilica moquaoximayatzi an tinoMatzin titon palacizco nepapan cozcatl y ylacatziuhqui mocacalatzin y ayeo ho aya yeha. Ahua teotle xiuhtotoahuachpixahuia a $\hat{y}$ motlayocol tihuanitziny tiquimilnamiqui miccatzitzinhuane ye iquiapam ycelteotl y quixoxochimacato in tlatohuani yehuan pelaloz ahua tocnihuane

57 Cantares mexicanos 1994, fol. 47v, trad. de la Autora.

58 Sahagún 1950-1982, VIII: 10.

59 García IzCABALCETA 1941, 3: 273 en: Bierhorst 1985: 125. 
¡Baila! ¡Ojalá tu dolor acabe! ¡Que suenen tus manos del ungido! Eres mi mano preciosa, oh don Francisco. Varios collares enredaron tu sonaja de barro. Oh Dios, cae el rocío de las aves de turquesa... Oh Huanitzin, con tristeza recuerdas a tus hermanos menores en el lugar de lluvia del Dios Único. Fueron a dar flores al que es Gobernador y Emperador, ¡oh amigos! ${ }^{60}$

Diego Huanitl, evocado aquí en forma reverencial como Huanitzin, tomó el trono de Tenochtitlan en la mitad de los años treinta del siglo XVI. El poder le fue concedido por el Virrey de la Nueva España, pero logró aceptación también entre las élites indígenas, que consideraron a ese nieto del huey tlatoani antiguo, Axayacatl, el heredero legítimo del trono mexica. ${ }^{61}$ Murió entre 1539 y 1541.

En lo que toca al enigmático don Francisco, mencionado en la primera parte de este fragmento, los autores de la traducción más reciente del manuscrito no comentan nada al respecto de su identidad, pero John Bierhorst sugiere que el contexto indica que se pueda tratar de algún cacique tepaneca desconocido, que probablemente gobernaba en Azcapotzalco alrededor de $1530 .{ }^{62} \mathrm{No}$ obstante, en mi opinión, hay por lo menos tres posibilidades más.

Una de las opciones, es que se trate aquí de don Diego de San Francisco Tehuetzquititzin, nieto de otro de los huey tlatoque prehispánicos, Tizoc, y el sucesor de Diego Huanitzin en el cargo del gobernador de Tenochtitlan entre 1541 y 1554 . Dada la composición de esa parte del canto -donde se recuerdan los gobernantes fallecidos de las tres ciudades-miembros de la antigua Triple Alianza- su evocación en este lugar, después de los gobernantes de Tlacopan y Texcoco, parece lógica. Cierto problema es que, en tal caso "Francisco" se referiría al apellido y no al nombre del personaje, lo que, sin embargo, contradice el uso del título "don", que en castellano antecede a los nombres y no los apellidos. Esto significa que para defender esta identificación, se tendría que suponer aquí un error del escribano, que en el caso del manuscrito discutido no sería un incidente aislado.

Por otro lado, entre los gobernantes indígenas que ejercían sus cargos en los primeros treinta años después de la conquista, es decir, el periodo del que datan los demás personajes mencionados por este canto, se encuentra también don Francisco de Sandoval Acacitzin, el tlatoani de Tlamanalco. De acuerdo con las informaciones proporcionadas por Chimalpahín e Ixtlilxochitl, Acacitzin tomó el poder bien justo antes o muy poco después de la conquista y,

${ }^{60}$ Cantares mexicanos 1994, fol. 47v., trad. de la Autora.

${ }^{61}$ Chimalpahin Quauhtlehuanitzin 1998: 169; Alvarado Tezozomoc 1975: 164; Alva IXTLILXOCHITL 2000: 202, en: MADAJCZAK 2006: 42-43.

${ }^{62}$ LeÓn-Portilla et al. 2011: 1207; Bierhorst 1985: 123 
gracias a la colaboración bastante fiel con la administración española logró mantenerlo hasta $1554 .{ }^{63}$ Fue, pues, como Huanitzin, un gobernante aceptado por ambas partes.

Finalmente, tampoco se puede excluir la posibilidad de que se trate aquí de uno de "la gente de la iglesia" que prepararon y guiaron este canto, especialmente tomando en cuenta que los Anales de Juan Bautista mencionan a dos personas de este nombre, concretamente a don Francisco Quetzalayatl y don Francisco Matlalacaca. ${ }^{64}$

Esta parte "histórica" del canto parece tener una estructura que corresponde a la cronología de los acontecimientos memorizados por los testigos de los cambios drásticos de los años directamente siguientes a la conquista. Empieza con la evocación de los gobernantes de Coyoacan, es decir, el lugar donde Cortés se estableció en 1521 después de la caída de Tenochtitlan y donde emprisionó a los representantes de la alta nobleza indígena, entre otros a Cuauhtemoc. Quauhpopoca pertenece todavía a los tiempos de la guerra contra los españoles: es uno de los mensajeros de Motecuhzoma que fueron a darle la bienvenida a Cortés recién llegado a la costa de Veracruz y uno de los primeros nobles matados por los conquistadores. Su hijo y sucesor en el trono de Coyoacan, Cetochtzin, compartió la suerte del padre muy poco después, durante la ejecución de los últimos gobernantes indígenas electos de acuerdo con las leyes de sucesión prehispánicas, ordenada por Cortés durante su viaje a Honduras en 1525. Luego se evocan los gobernantes de Tlacopan y Texcoco, es decir dos de las tres ciudades de la antigua Triple Alianza, que fueron ya impuestos por los españoles y que ejercieron sus cargos durante muy poco tiempo entre 1526-1530/31. El primero, Yoyontzin, muere por causa de la epidemia causada por los microbios europeos, el segundo, Gabriel, es llevado por Cortés a España. Dadas las condiciones socio-políticas penosas que acompñaban el tiempo de su gobierno, así como el hecho de que los dos terminaron su vida de modo prematuro y por culpa de los europeos, parece lógico que tanto Yoyontzin como Gabriel llegaran a convertirse en símbolos del caos e inestabilidad, que reinó en aquellos años. Como observa Julia Madajczak ${ }^{65}$, solo con la toma del poder por Huanitzin y después por San Francisco, la situación empezó a estabilizarse. De esta manera, la evocación de esos dos gobernantes al final de ese pasaje sería un signo de la restitución del orden trastornado. Por otro lado, un papel simbólico parecido podrían desempeñar también Juan de Guzmán Itztlolinqui y Francisco de Sandoval.

${ }^{63}$ Alva Ixtlilxochitl 2000: 318; Chimalpahin Quauhtlehuanitzin 2003: 207, en: MaDAJCZAK 2006: 85-86.

${ }^{64}$ ReYes García 2001: 165 (fol. 10v).

${ }^{65}$ Comuncación personal, octubre 2019. 
La cuestión que queda por resolver es si don Francisco y Diego de Huanitzin estaban vivos o muertos en el momento de la entonación del canto. En el caso de este ultimo, las metáforas utilizadas indican bastante claramente, que se trata de uno de los moradores del más allá. "Cae el rocío de las aves de turquesa..." dice el canto. Ya se ha comentado la asociación de las aves con los espíritus de los que han tenido la muerte gloriosa. La palabra xihuitl - "turquesa" en los ojos de los españoles bien podía corresponder con la noción del agua de rocío. En la ideología indígena prehispánica, no obstante, como ya se ha mencionado, estaba asociada con el fuego y con la nobleza. Como informa Diego Durán: "Al fuego llamaban Xiuhtecuhtli, debajo del cual nombre le adoraban y hacían grandes ofrendas." ${ }^{67}$ Por otro lado, los informantes de Sahagún entre varios nombres dados al Sol enumeran a Xiuhpiltontli "68 "El Joven de Fuego". Las aves de turquesa que caen como el rocío son, pues, las aves del fuego que viven al lado del Sol y comparten su naturaleza. Entre ellos se encuentra Huanitzin y los demás señores conmemorizados en este canto, que ahora vienen bailando a recibir en su compañía al Presidente. Esta imagen, verbalizada en el canto analizado, corresponde muy bien con la descripción de la muerte de Quetzalcoatl proporcionada por los Anales de Cuauhtitlan que, según Johansson, era para los nahuas un modelo arquetípico, a partir del cual se crearon luego los ritos funerarios de la nobleza mexica:

[...]... se narra que habiendo llegado al mar, a la orilla del agua-cielo, se paró, lloró, cogió sus pertenencias, aderezó su insignia de plumas, su máscara de turquesa, etc., y cuando hubo terminado, él mismo se prendió fuego y se quemó (...) Se dice que cuando arde, luego se elevan sus cenizas, y que veían todas las aves preciosas, que pasan arriba en el cielo: veían el tlauhquechol, el xiuhtototl, el tzinitzcan, los papagayos, tozneneme, allome y cochome, y muchos otros pájaros hermosos. Al acabarse [de hacerse] sus cenizas, luego aparece en lo alto el corazón del ave quetzal, lo ven. Según sabían, fue al cielo y entró en el cielo. Decían los viejos que se convirtió en la estrella que al alba sale; así dicen que apareció cuando murió Quetzalcoatl, a quien nombraban el Señor del Alba [Tlahuizcalpantecuhtli $]^{69}$

Huanitzin recuerda a sus hermanos menores permaneciendo en el "lugar de lluvia del Dios Único", es decir, en el cielo, al que se elevaron sus cenizas

${ }^{66}$ La palabra xihuitl tiene en realidad más significados, los principales siendo: "año", "hierba" y "turquesa".

${ }^{67}$ Durán 1967, I: 128. Xiuhtecuhtli significa literalmente "El Señor de Turquesa/Año", véase también: SAHAGÚN 1950-1982, I-29 3064 72, II-115 129159160161162168190 209, entre otros.

${ }^{68}$ Sahagún 1950-1982, II: 216.

${ }^{69}$ Anales de Cuauhtitlan, en: JoHANSSON 2016: 216-217 
igual que las de Quetzalcoatl. No obstante, hay que recordar, que también en el cristianismo, el rocío y la lluvia provienen del Cielo, que es la morada de Dios, como lo afirman varios pasajes de la Biblia, como por ejemplo:

Jehová tiene en el cielo su trono; Sus ojos ven, sus párpados examinan a los hijos de los hombres. ${ }^{70}$

Porque Jehová me dijo así: Me estaré quieto, y los miraré desde mi morada, como sol claro después de la lluvia, como nube de rocío en el calor de la siega. ${ }^{71}$

Yo seré a Israel como rocío; él florecerá como lirio, y extenderá sus raíces como el Líbano. ${ }^{72}$

Allá, los nobles indígenas que murieron van a hacer ofrendas floridas al pelaloh. La palabra pelaloh no existe en náhuatl, es una transcripción errónea de algún término castellano. León-Portilla propone que es "prelado" y se refiere al mencionado Sebastián Ramirez de Fuenleal, quien además del Presidente de la Segunda Audiencia era también obispo. ${ }^{73}$ Entonces los nobles muertos, como las aves preciosas del mito de Quetzalcoatl, vienen a darle la bienvenida a Fuenleal, quien acaba de unirse con ellos en el más allá del Cielo.

En lo que toca a don Francisco, tomando en cuenta el hecho de que su identidad, a pesar de las suposiciones hechas arriba, permanece desconocida, tampoco es posible decir con toda la certeza si en el momento de la entonación del canto estaba vivo o muerto. Sin embargo, las palabras que pronuncia el cantor, tal vez Itztlolinqui, parecen indicar que se trata de la persona viva: “¡Baila! ¡Ojalá tu dolor acabe! ¡Que suenen tus manos del ungido! Eres mi mano preciosa, ¡oh don Francisco! Varios collares enredaron tu sonaja de barro." Es en tanto más probable que los últimos versos de esa parte del canto parecen ser una respuesta de don Francisco dada a Itztlolinqui:

Tinoteycatzini ye titztlolinqui ma tihuiya .S. Palacizco ma tiquittati totlaçotatziny toconmacazque tocacalatzin y oncã no cenquiça y tepilhua ahua tocnihuane

Mi hermano menor, Itztlolinqui, vayamos a San Francisco, veamos a nuestro venerado padre, le daremos nuestras sonajas. Allá se juntan los niños, ¡oh amigos! $!^{74}$

\footnotetext{
${ }^{70}$ La Biblia de las Américas, Salmos 11: 4

${ }^{71}$ La Biblia de las Américas, Isaias 18:4.

${ }^{72}$ La Biblia de las Américas, Oseas 14:5.

73 León-Portilla et al. 2011: 1208.

${ }^{74}$ Cantares mexicanos 1994, fol. 47v, trad. de la Autora.
} 
La conversación se da entre los nobles de la clase gobernante que se dirigen uno al otro con el término teiccauh, "hermano menor", que en los documentos coloniales podía tener el valor parecido a icniuhtli, "amigo", denotando la relación de igualdad o dependencia entre los hablantes. ${ }^{75}$ Don Francisco anima a Itztlolinqui a que vayan a presentarse con sus sonajas al convento de San Francisco. Allá los espera su padre, fray Pedro de Gante, quien reune a su lado a los "niñitos" indígenas.

Ahora, si aceptamos, que don Francisco era un participante vivo de la celebración y que era uno de los dos personajes de la clase gobernante mencionados arriba, hay que reconsiderar la fecha de la entonación del canto analizado. Tanto Francisco de Sandoval, como don Diego de San Francisco mueren en 1554 y, por lo tanto, no podrían asistir a la ceremonia descrita en los Anales de Juan Bautista bajo la fecha de 1567. Además, si aceptamos que el Presidente evocado por el canto fue, efectivamente, Sebastián Ramírez de Fuenleal, la fecha de su muerte en 1547 hace posible que el canto en su conmemoración se haya compuesto varios años antes de 1567. En la tradición oral la reelaboración y adaptación de los modelos anteriores a las necesidades nuevas no es nada extraño y la información proporcionada por el título del canto parece indicar que este fue, efectivamente, el caso. El título dice explícitamente que es: Piltoncuicatl ye huecauh, "Canto de niños de los tiempos pasados". Después explica que el contexto de la representación de esta versión concreta es más temprano: meuh ompa Mexico S. fr $r^{\mathrm{co}}$ ypan ilhuitzin tomatian, "Se elevó allá en México en la fiesta de San Francisco en nuestros tiempos". Se nota pues una distincción bien clara entre el tiempo de la composición del canto, precisado una vez más en la última parte del título - mochiuh yquac in ompa teopan tinemia oc tipipiltotontli, "se hizo cuando vivíamos en la iglesia todavía como niñitos" - y el tiempo de su entonación en la versión que quedó plasmada en el manuscrito de Cantares mexicanos. En otras palabras, si es bien probable que el canto mencionado por los Anales de Juan Bautista y el transcrito en Cantares sean registros de la misma representación, esto no quiere decir que sea esta la única o la primera. Tomando en cuenta los datos mencionados, lo que parece mucho más probable, es que la composición en cuestión fue creada más o menos veinte años antes, con motivo de las exequias de Ramírez de Fuenleal, tal vez también a partir de algunos modelos más antiguos. En aquel entonces los dos posibles Franciscos todavía estaban vivos y pudieron participar en la celebración así como lo sugiere el texto.

${ }^{75}$ MADAJCZAK 2014: 251. 
Los versos que siguen vuelven por un breve rato al tema de culto de San Francisco:

\section{Tiquitocotiquitoco tititi}

Y xihuallaquican tonahuac onoque ye ilhuitl aya tiquixtiliya o anqui tozcacauhtzin.S. Palacizco ya anqui ye axcã ye itech ahcic ymahuiçon dios teucyotl oo anqui tlatocayotl ylhuicatlytec çaquãcalco quetzalcalitec conayatlali ycelteotl y ma ycaya an netlamachtilo y tipipiltzitzinti ya. Ma ya papaquihua Ma ic momalina tlayocolia techtlamacehui o anqui ye tozcacauhtzin.S. Palacizcoya anqui ye axcan Etc.

¡Venid los que cerca de nosotros estáis! Ya es el día en que honramos a nuestro padre, San Francisco. Llegó a la gloria de Dios. El señorío y el mando en el cielo, en la casa de zacuan, en la casa de quetzal, lo estableció el Dios Único. ¡Ojalá que haya gozo y riqueza, somos niñitos! ¡Que haya alegría! ¡Que se entrecruce con la tristeza! Esto es lo que se nos merece. Hoy nuestro padre San Francisco, hoy llegó... Etc. ${ }^{76}$

Es la primera vez que tan directamente se indica a la fiesta de San Francisco como el contexto de la entonación. Los versos que siguen mantienen este estilo, siendo una suerte de la profesión de fe cristiana:

$\hat{Y}$ tlaçoteuctle Diose ayc tipeuh ayc titzintic ça cemicac huel moyeya ilhuicatl ytec oncã tlatoa yeccanaya in moch motlachihual yn ilhuicatl y nica maniyã tlalticpac aya yca nichoca niquaoxitzin oho huio michi mohueli ya oo huio mocha mohueli yya. Chalchihuitla quetzalayahuitla yca ontzauctimani o anquin ye mocha aya. in moch motlachihual yn ilhuicatl Etc.

Oh Señor Precioso, oh Dios, tú nunca comenzaste, nunca tuviste principio, sino que siempre estuviste dentro del cielo. Allá gobiernas, en este lugar bueno. Todo es tu criatura: el cielo y la tierra, que aquí se extiende. Lloro yo Quaoxitzin, ;oh Todopoderoso, oh Todopoderoso! Entre las piedras preciosas, en medio de la niebla preciosa se extiende, está encerrada tu casa. Todo es tu creación, el cielo... ${ }^{77}$

Las palabras que acaban esta parte son bastante oscuras y una interpretación unívoca de ellas resulta difícil. A primera vista parecen volver al tema del nacimiento del Cristo en la tierra:

Quetzaltoztli nicmemeya tixalmelolo nomache anca ço nellin tiquehcahuico yectli ye mocuic huico huicon tilili o aye xonahuiacana. $\hat{Y}$ maoc onehualo yectli yan cuicatl y anca ço nelli ye ic concuico tipipiltzitzinti totecuehuetzin toquauhcoyoltzin huihco huihcon tilili oaye.

76 Cantares mexicanos 1994, fol. 48r, trad. de la Autora.

77 Cantares mexicanos 1994, fol. 48r, trad. de la Autora. 
Llevo a cuestas al papagayo amarillo precioso. Has sido echado en la arena, oh sobrino mío. Por eso, seguramente, vienes trayendo tus buenos cantos. Son llevados, son llevados, ¡alegraos! ¡Levántense los buenos cantos! Tal vez así sean cantados, oh niñitos: el tambor señorial, nuestras sonajas de madera son llevados, son llevados. ${ }^{78}$

Se mantiene el ámbito de la fiesta y canto. Quetzaltoztli es una palabra formada por quetzalli, ,pluma preciosa" y toztli "papagayo de plumaje muy amarillo y resplandeciente"79 (y por extensión "cosas amarillas"). En conjunto podría ser traducido como "ave/cosa preciosa, amarilla y resplandeciente" y funcionar como una metáfora del Niño Jesús. Esta hipótesis interpretativa la apoya, al parecer, la frase que sigue. El cantor se dirige en ella al que "ha sido echado en la arena" y unos versos más arriba fue el Niño Jesús quien estaba descrito como "el que va a descender sobre arena" (xaltemocto).

Por otro lado, como se ha explicado anteriormente, una de las características de la tradición oral es la reelaboración de los modelos antiguos para los fines nuevos. Lo que quiero proponer aquí es que el fragmento citado arriba y el que sigue podían formar parte de un canto originalemnte mucho más antiguo, tal vez relacionado con los rituales celebrados cada cuatro años durante el mes Izcalli. Era el tiempo cuando se sometía a los niños pequeños a una serie de ritos que los incorporarían a la sociedad y propiciarían su crecimiento. Entre otros, como reportan los informantes de Sahagún, se los decoraba con plumas amarillas de papagayo toztli para someterlos al rito de agujeramiento de las orejas. Después de la adaptación a las necesidades cristianas, esa imagen del niñito bellamente ataviado con plumas resplandecientes del color del Sol y del oro, bien podía llegar a convertirse en la metáfora del Niño Jesús.

No obstante, este no es el único vinculo con Izcalli que se ve en este canto, pues los versos que siguen dicen:

\section{Tocoto Cotiti tocoto cotititi quiti quiti}

$\hat{Y}$ ma õnahahuialo ticcahua o antecpilhuani $\hat{y}$ ma hualnequetzalo $\hat{y}$ ma ya oncenpãtihua tictlatlauhtizque ycelteotl y çanio y ye oncã ytloc y nahuaque ao ceceliztoqui a yn iye xochitl oncã toconhutequizque in tecoçauhtic xochipapalotl ohaye ho aya yeha. Tlatlapalpoalti a $\hat{y}$ pipiltzitzinti y huexotzincay camohpaltic huitztecolxochipaltic aya ixpan onquiça ycelteotl y çanio y ye õcã çan tzinitzcã y celizticac ooy cempoalxochitl.

¡Que haya alegría! ¡Somos hermanos! ¡Sois príncipes! ¡Hágase el levantamiento! ¡Hágase el ordenamiento en una fila! Le rogaremos al Dios Único, solamente allí, cerca de Él, junto a Él están brotando las flores.

${ }_{78}$ Cantares mexicanos 1994, fol. 48r, trad. de la Autora.

79 SAHAgún 1950-1982, XI: 23. 
Allí mataremos esta mariposa florida de color dorado. Listados de diversos colores son los niños huexotzincas: con el color morado oscuro, con el color de las flores naranjas. Salen a la presencia del Dios Único. Sólo allá están brotando las plumas de trogon y las flores de cempoalxochitl..$^{80}$

Como ya se ha mencionado anteriormente, Izcalli era la fiesta celebrada en honor al dios del fuego, conocido como Xiuhtecuhtli, "El Señor de la Turquesa" o, bajo otro nombre, como Ixcozauhqui, "El de la Cara Amarilla/Dorada". Dado el color amarillo o dorado de esa segunda personificación de la divinidad, no es de extrañar que uno de los materiales utilizados en la decoración de la figura del dios eran las plumas del papagayo toztli. ${ }^{81}$ Si normalmente durante esta fiesta no se sacrificaban víctimas humanas, cada cuatro años el evento tenía una forma particular. Se mataba entonces a los personificadores de Ixcozauhqui, denominados en el Códice Florentino como tlaaltilti, "los bañados" que, como ya comentamos más arriba, iban a transformarse en el planeta Venus. Como informa la fuente en cuestión, los bañados eran primero metidos en la arena, igual que "el sobrino" invocado en el canto analizado. El canto añade: "Has sido mezclado con la arena, sobrino mío, por eso ciertamente llegas a hacer tus buenos cantos" y los informantes de Sahagún explican que:

Cuando amanecía los adornaban otra vez. Los llevaban al lugar donde iban a matarlos, todos estaban en orden. Allí todos ellos bailaban y cantaban, se esforzaban mucho. Se decía que cantaban hasta que sus voces se ponían roncas. ${ }^{82}$

Después, las futuras víctimas eran ordenadas en una sola fila y llevadas en procesión por el sacerdote, que representaba al dios Painal, hacia la piedra sacrificial. Los llamamientos que aparecen en el canto “¡Hágase el levantamiento! ¡Hágase el ordenamiento en una fila! Le rogaremos al Dios Único, solamente allí, cerca de Él, junto a Él están brotando las flores" parecen corresponder con esta parte del ritual, mientras que la frase que sigue: "Allí mataremos esta mariposa florida de color dorado/amarillo", sería una referencia al sacrificio de los personificadores del dios del fuego ${ }^{83}$ Como ya se ha indicado, la mariposa, era uno de los símbolos del fuego, y al parecer también uno de los símbolos importantes en las celebraciones de Izcalli, como se puede notar en la representación gráfica de esta fiesta en el Códice Borbónico [fig. 18].

${ }^{80}$ Cantares mexicanos 1994, fol. 48r, trad. de la Autora.

81 SAHAGÚN 1950-1982, II: 161

82 SAhagún 1950-1982, II: 163, trad. de la Autora.

${ }^{83}$ Por supuesto no se puede excluir la posibilidad de que este sentido original fue luego extendido para referirse metafóricamente, por ejemplo, a la Pasión de Cristo. 


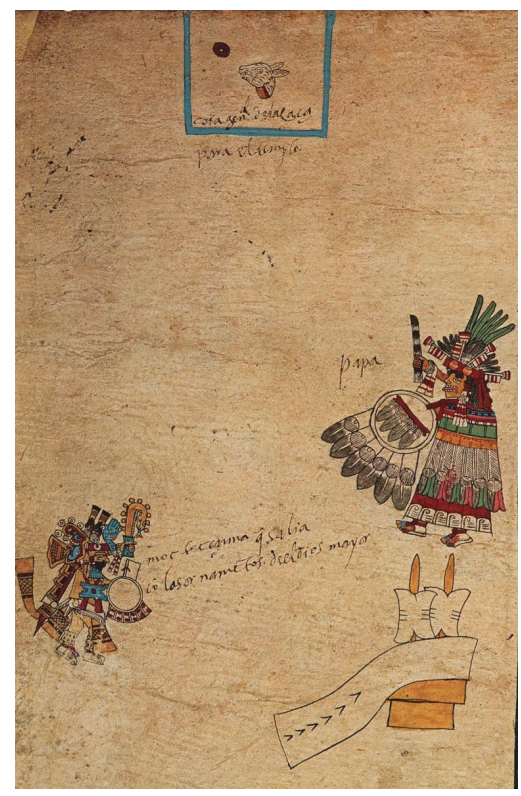

Fig. 18. La fiesta de Izcalli, Códice Borbónico 1980, lam. 23.

Los versos que siguen, aunque a primera vista parecen describir la procesión de las almas salvadas que llegan a la presencia de Dios, igualmente bien corresponden con el ambiente festivo de Izcalli:

Ontozyhuimomoyahuatimani ye oncany çan can xiuhquecholayauhtonã $\hat{y}$ mamatlallahuizcallehuatoc ytech ye oncuica teocuitlachopiltzi quimonahuiltia y ye ixquich ytlaçohua ye iquecholhuã Dios hoaye hoaya yha. Ma xihualla'lacan papalome o antla 'tlachichina ye onnetlamachtilo ye iquiapa Xesuchristo ye ixquich ytlaçohua Etc.

Se dipersan las plumas del papagayo amarillo, allá en la niebla brillan los quecholes de turquesa. Por las gradas de la aurora se elevan a Él. Canta el grillo dorado, les da la alegría a todos sus preciosos, a los quecholes de Dios. ¡Venid mariposas, chupadoras! Hay riquezas y alegría en el lugar de la lluvia de Jesucristo, todos sus preciosos Etc. ${ }^{" 84}$

Por un lado, vemos aquí la gloria y todos los gozos del paraíso que se abren ante las almas salvadas, "los quecholes de Dios". Esa imagen prometedora, empleada aquí en servicio del cristianismo, al mismo tiempo corresponde muy bien con las descripciones de la Casa del Sol: los muertos se encuentran en el Este, convertidos en los pájaros y con el amanecer inician su camino por el cielo, se elevan. Se elevan como las cenizas de Quetzalcoatl para llegar al interior del cielo y convertirse en los quecholes preciosos.

${ }^{84}$ Cantares mexicanos 1994, fol. 48r, trad. de la Autora. 
Con los versos que siguen vuelve el ambiente puramente cristiano: $\hat{Y}$ tlapalamoxtli moyollan tipala petolo $\hat{y}$ quexquich mocuic $\hat{y}$ toconehuilia Xesuchristo çan tocontlayehecalhui in .S. Palacizco ya ic nemico tlalticpac a o anqui ya nella nomache. $\hat{Y}$ huel melel ahciticac tipala petolo $o$ antle toayacach in quenin tahahuiazque in tipipiltzitzinti çan tocontlayehecalhuiya Etc.

¡Como la pintura de colores es tu corazón, oh Padre Pedro! ¡Cuántos son los cantos que elevas a Jesucristo! Imitas a San Francisco, su vida en la tierra, así realmente es, oh sobrino mío. Gran pena está viviendo Padre Pedro, nada son nuestras sonajas. ¿Cómo nos alegraremos, nosotros los niñitos? Imitas... Etc..$^{85}$

Fray Pedro de Gante, el personaje evocado en este fragmento, está presentado como el que vive la vida santa, llena de pena y austeridad, siguiendo el ejemplo del patrono de la órden, San Francisco. Los indígenas se presentan como sus niños: están aprendiendo una vida nueva, pero les falta mucho - nada son sus sonajas. En toda la parte que sigue otra vez se describe el ambiente festivo, paradísiaco:

\section{Totocoto tototo cototo titiquititi titiqui titiquito}

$\hat{Y}$ ma onnetotiloya aya tomachvan anpipiltzitzinti o ontzitzinitzcaxochiaonilacatziuhtihui çan toxochiamoxcuic Ma toconahuiltica aya totatzin yehuayan dios ya ontzitzinitzcaxochiaonilacatziuhtihui Etc. $\hat{Y}$ mecatzitzine $\hat{y}$ tla tohuiya $\hat{y}$ xomilpã ycelteotl y ompa tocontahuiltizque huel tecemelti tlatlatzcatimani ahuili xochitl ahuiac xochitl aya tocontehtequizque $\hat{y}$ tipipiltzitzinti yanca yyahue. Onitzmolintoc yxochiuh in Dios y yyetlauhquecholatlatzonpil in i piliuhticac quilloticac aya tocontetequizque.

¿Que haya baile, sobrinos nuestros, niñitos! Como plumas de trogón en el agua florida vienen torciéndose nuestros cantos en pinturas floridas. Alegremos a nuestro padre Dios. Como plumas de trogón en el agua florida vienen torciéndose. Guirnaldas, vayamos a las milpas verdes del Dios Único, allá lo alegraremos. Lo alegramos mucho, hay un gran ruido. Las flores de alegría, las flores olorosas, las cortaremos nosotros los niñitos. Yerguen sus brotes las flores de Dios, sus plantas atlatzompilli de color bermejo $^{86}$, están marchitas y henchidas, las cortaremos. ${ }^{87}$

${ }^{85}$ Cantares mexicanos 1994 fol. 48r-48v, trad. de la Autora.

${ }^{86}$ La palabra tlauhquecholatlatzonpil está compuesta de tlauhquechol - un nombre de espátula rosada, pero traducido por Molina también como un indicador de color bermejo: ,pluma rica y bermeja" (Molina 1992, 2:144v) - y la palabra atlatzonpilli, que designa una flor de color rojo intenso, cuyo color los informantes de Sahagún comparan precisamente con las plumas de tlauhquechol (SAHAGúN 1950-1982, XI: 207).

87 Cantares mexicanos 1994, fol. 48v, trad. de la Autora. 
Finalmente, en la última parte del canto, casi como un acento que debería dejar a los indígenas con las asociaciones "adecuadas", es decir cristianas, aparece el motivo de San Cristobal:

Tico tico tiquiti tiquiti Etc.

Xochiaatepa panahuiya oo .S. Quilistopal ça ye quipanahuiya o yn tlaçoteotl Jesu Quilisto xochinpapalomatlahuique. Xochiatempan çan mitztlacanotza y yehuan Dios.S. Quilistopal çã ye ixquich oo ca ye o ticnapaloa yn ilhuicatl o y cemanahuaqui xochipapalo Etc.

Por el agua florida pasa San Cristobal, trae al dios precioso Jesucristo. Cazaron las mariposas floridas. En el borde del agua florido te habla en persona Dios, oh San Cristobal: "Lo llevas todo en tus hombros: el cielo y el mundo." Las mariposas floridas Etc. ${ }^{88}$

Aunque el canto se mantiene en el ambiente del agua florida y caza de mariposas, el texto es, en realidad, una traducción de la leyenda de San Cristobal.

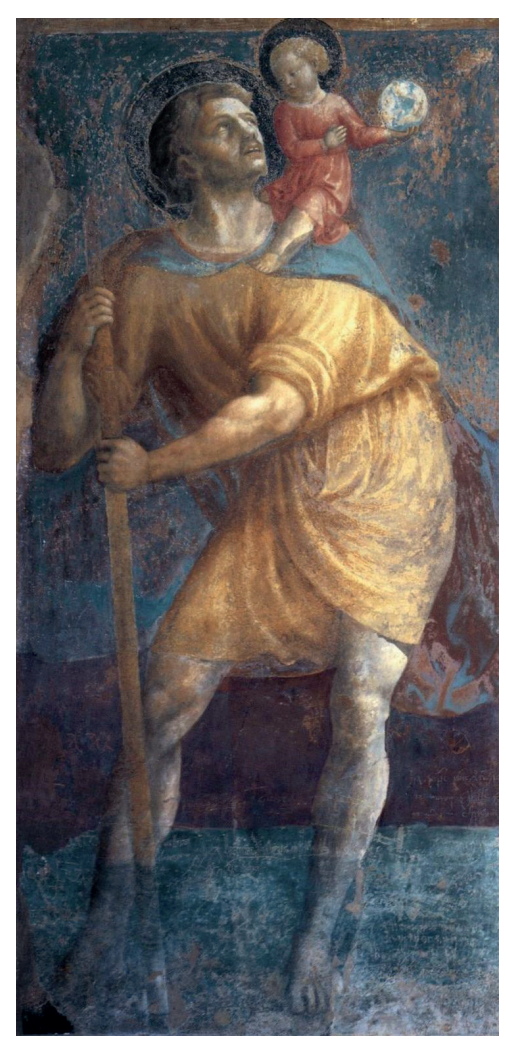

De acuerdo con la tradición cristiana, este gigante decidió servir a Dios ayudando a la gente cruzar un río grande y peligroso. Un día encontró en el borde del agua a un niño pequeño que le pidió ayuda en el pasaje. Cuando estaban en la mitad de la travesía, San Cristobal se dio cuenta de que con cada paso el niño pesaba más. Al llegar al otro lado, le dijo al pequeño que creía llevar el mundo entero sobre sus hombros. El Niño, que en realidad era Jesús, le respondió: "Y lo has llevado, porque yo soy el Dios Creador del mundo entero" [fig. 19]. ${ }^{89}$

Fig. 19. Tommaso di ser Giovanni di Mone Cassai (Masaccio), San Cristobal, 1425-1431, San Clemente, Roma, Italia.

${ }^{88}$ Cantares mexicanos 1994, fol 48v, trad. de la Autora.

${ }^{89}$ Brugada 2013. 
Además, de acuerdo con varias leyendas medievales, San Cristobal tenía una cabeza de perro y solo después de su encuentro con Jesús, cuando tomó el bautismo, recibió de modo milagroso el aspecto humano. Por lo tanto, en la iconografía el santo en cuestión aparece a veces representado con la cabeza del perro [fig. 20].

Fig. 20. San Crisobal cinocéfalo.

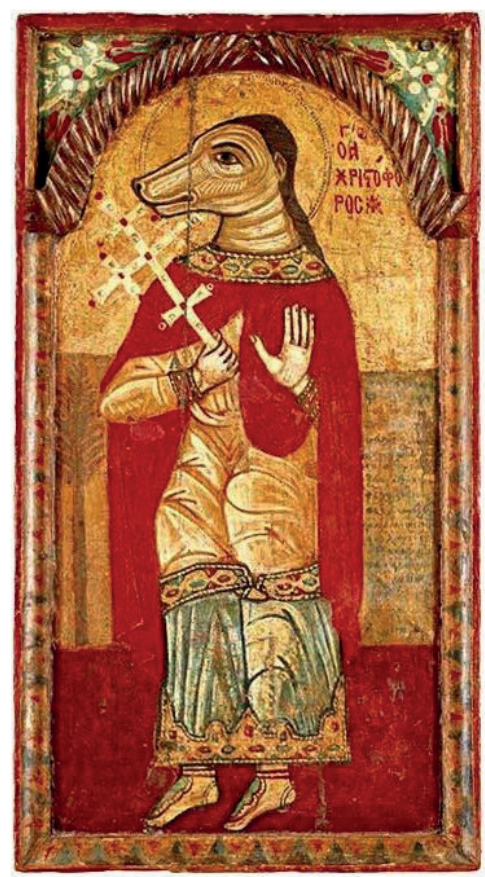

Esas leyendas medievales sirvieron, entre otros, para reemplazar las creencias antiguas sobre los seres sobrenaturales que ayudaban a los muertos en su paso al más allá, como los mitos griegos de Caronte o la figura de Anubis en el antiguo Egipto [fig. 21]. Me parece digno de señalar que una transposición parecida pudo haberse producido también en la cultura indígena recién cristianizada. En las antiguas creencias mexicas, el pasaje al otro lado del oceáno lo podían facilitar varios seres marinos, como en el mito de Yohualli Ehecatl citado más arriba, mientras que el cruce del río de Mictlan lo facilitaba el perro llamado xoloitzcuintli [figs. 22, 23 y 24]. Si tomamos en cuenta que, por lo menos en cierta parte, el texto analizado es un canto entonado en las exequias de Ramírez de Fuenleal, la evocación de San Cristobal podría interpretarse como el ruego dirigido a uno de los espíritus poderosos y mensajeros del mundo cristiano para que acompañe al muerto al otro lado de la realidad. 


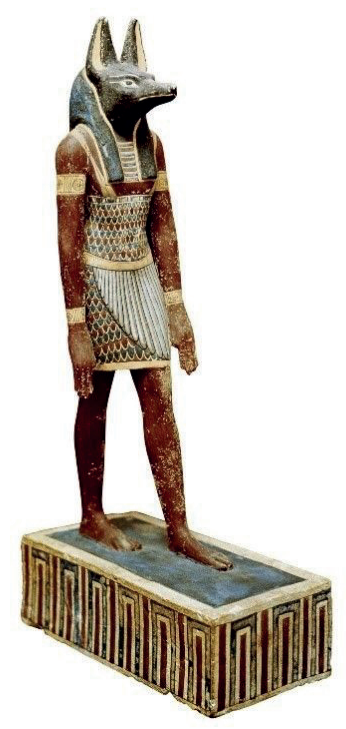

Fig. 21. Estatuilla de Anubis en madera y estuco.

Fig. 22. Xoloitzcuintli - el perro guía de los muertos. 


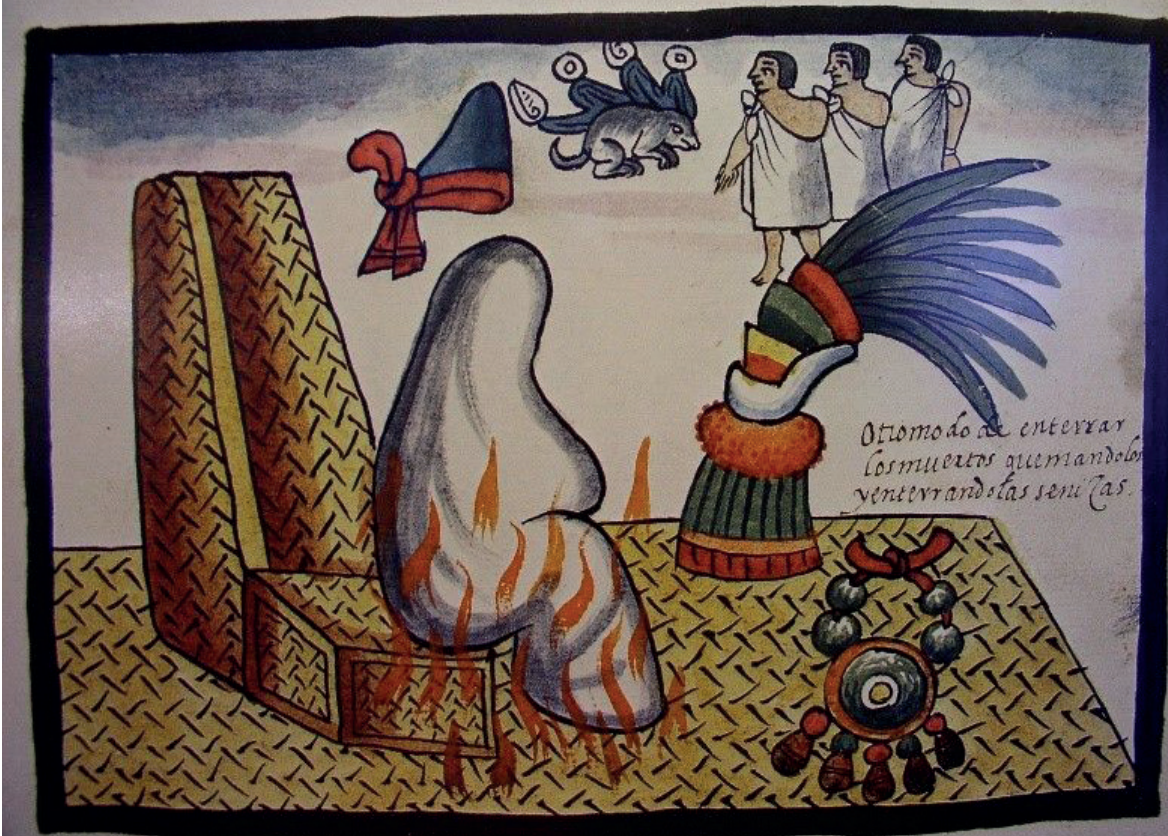

Fig. 23. En el centro: el bulto mortuorio durante el rito de incineración, arriba: xoloitzcuintli relacionado con el glifo del agua, Manuscrito Tovar 2001 p. 25.

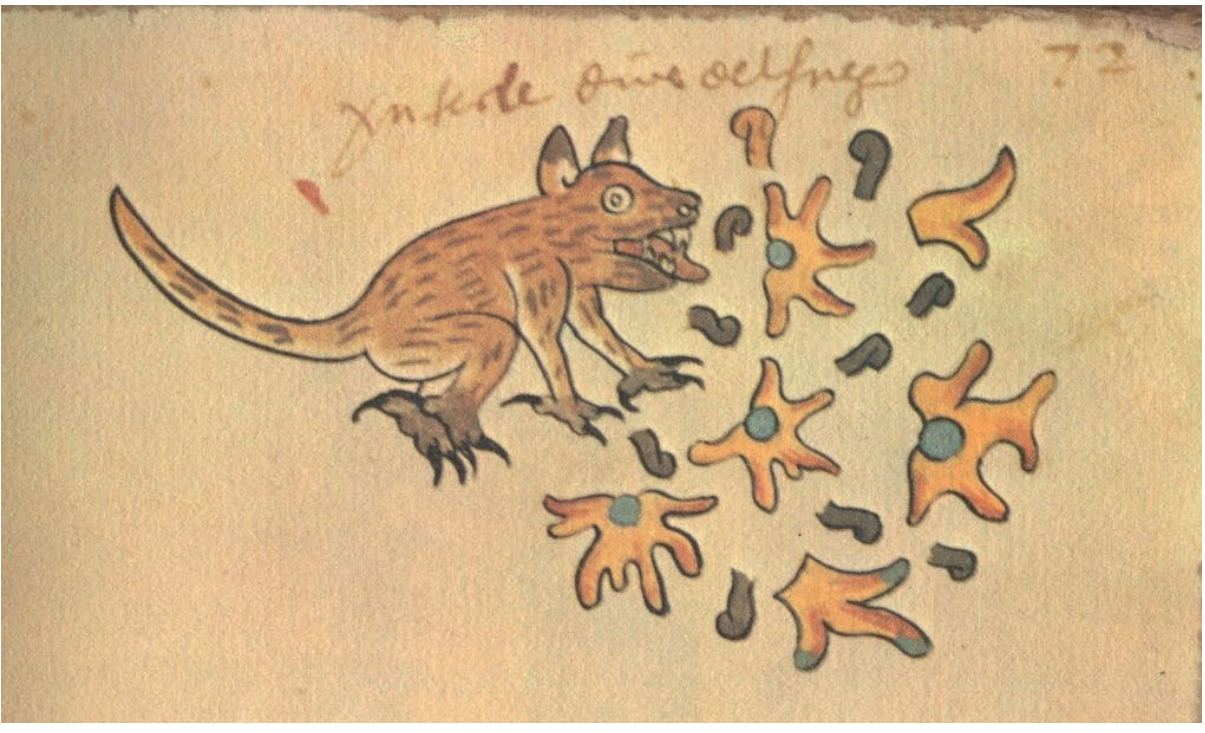

Fig. 24. Xoloitzcuintli y las llamas del fuego en forma de las mariposas estilizadas en una de las láminas dedicadas a los ritos mortuorios, Códice Tudela 2002, f. 72r. 


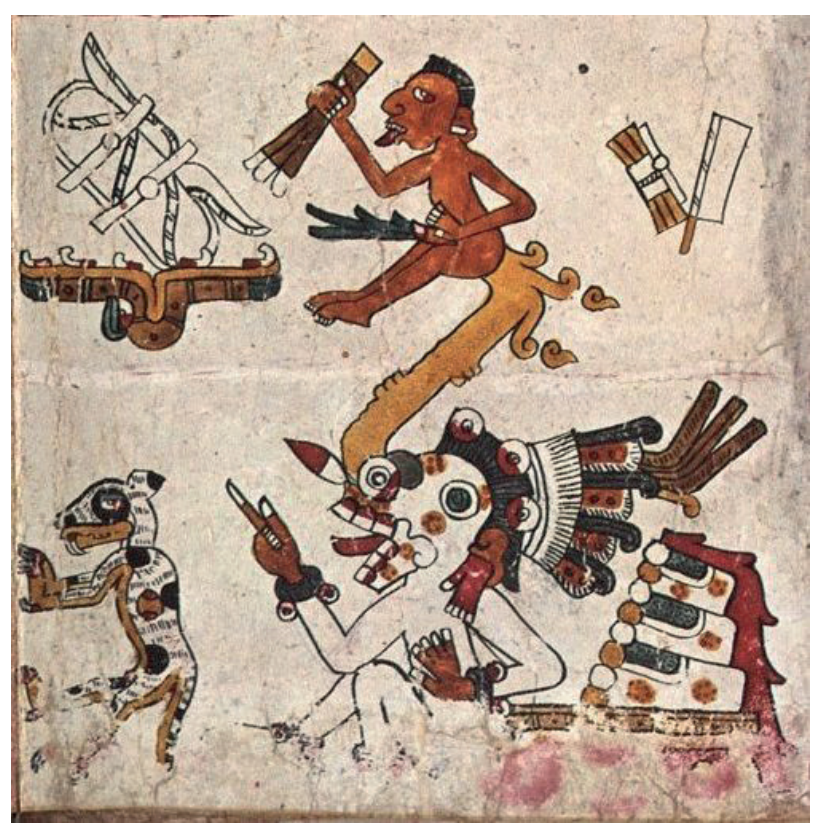

Fig. 25. Mictlantecuthli (a la derecha) y xoloitzcuintli (a la izquierda). Arriba: el monstruo de la tierra tragando el bulto mortuorio, Códice Borgia 1963, p.13.

Una vez entregado el muerto a las manos de los seres del más allá, los participantes vuelven al baile y canto, mantenido otra vez en el ambiente paradísiaco. Sin embargo, lo que se subraya aquí es también la espera a la llegada de Dios y la resurección de sus salvados al fin del mundo:

Xamelaquahuaca tihuexotzinca tipipiltzitzintine tla tontahuilticã ayyahue tla tonquetzalhuitzitzilpapalomatlahuicã tla tiquimõchiacan ayyahue in tlacaço no yehuatl in pala petolo in totlaçotatzin yqui tlatlatztihuitz in tocenteucyo ya icelteotl a. Tla tonhuiya hui tipipiltzitzinti tla tocontequicã tlapapalxochitl ma ic tontitotican yyahue in tlacaço no yehuatl.

¡Esforzaos! ¡Alegrémonos, nosotros los niñitos huexotzincas! ¡Cacemos mariposas, colibríes y quetzales! ¡Esperémoslos! Oh Padre Pedro, nuestro amado padre, ¿Cuándo venga entre truenos nuestro señor, el Dios Único? ¡Vayamos, vayamos, nosotros niñitos, cortemos las flores multicolores! ¡Bailemos! ${ }^{90}$

${ }^{90}$ Cantares mexicanos 1994, fol. 48v, trad. de la Autora. 


\section{CONCLUSIONES}

El Pilcuicatl, o "Canto de niños", al contrario de la gran mayoría de los cantos recogidos en el manuscrito de Cantares mexicanos, parece relativamente bien contextualizado. Lo mencionan los Anales de Juan Bautista como un canto ordenado por fray Pedro de Gante, preparado por sus alumnos indígenas y elevado en la fiesta de San Francisco en 1567. Esta información la apoya el título del canto, que proporciona los datos parecidos. No obstante, el análisis pormenorizado del texto ha revelado que el caso de esta obra es mucho más complejo.

Si bien se puede suponer con bastante probabilidad que la versión registrada en Cantares mexicanos podía ser la entonada en la fiesta de San Francisco en 1567, seguramente no fue el canto compuesto desde el principio para este fin. La gran diversidad de motivos que se entrecruzan, a primera vista de modo completamente caótico, revela la historia de la creación de este canto. Como una forma originalmente perteneciente a la tradición oral, "El Canto de Niños" lleva rastros no solo de la estética indígena y cristiana contemporánea al momento de su transcripción en alfabeto a finales del siglo XVI. Es un testimonio de los procesos de aculturación que se dieron en el momento del contacto de los dos mundos y pocos años después - un collage de fragmentos de varias formas antiguas, como los cantos de conmemoración de los nobles indígenas prehispánicos o un canto ritual vinculado a los sacrificios humanos del mes Izcalli, con las intromisiones típicamente cristianas, a veces hasta traducciones directas de la Biblia o del Credo.

Además, tomando en cuenta las fechas de vida y muerte de los personajes históricos evocados en esos versos, especialmente de Sebastián Ramírez de Fuenleal (1547), parece probable que en los tiempos de la colonia este canto fue entonado por lo menos dos veces: la primera entre 1547 y 1554 , y la segunda en 1567. La creación analizada debería ser considerada entonces un efecto y una muestra de los procesos históricos, políticos y socio-culturales muy dinámicos que tuvieron lugar en Nueva España en la segunda mitad del siglo XVI. Por lo tanto, no es posible proporcionar una sola e unívoca interpretación de este texto. Creo que los símbolos empleados en él conllevaban asociaciones distintas para diferentes miembros del público. Los españoles seguramente entendían las metáforas empleadas en este canto de modo distinto que sus alumnos indígenas, mientras que los participantes nativos recién "reclutados" y tal vez todavía no bautizados podían encontrar en ellas los significados bien conocidos de sus tradiciones antiguas e interpretar toda la inscenización a su propio modo. 


\section{Agradecimientos}

El análisis presentado en el presente artículo ha sido llevado a cabo como parte del proyecto de investigación The cultural topoi in the pre-Hispanic and early Colonial oral tradition of Central Mexico financiado por el Centro Nacional de Ciencia de Polonia (UMO-2018/28/C/HS2/00227). Quiero expresar mi agradecimiento a Agnieszka Brylak, Adriana Jastrzębska, Ewa Kubiak y Julia Madajczak por su apoyo, consejos y sugerencias.

\section{Bibliografía}

Alva Ixtlilxochitl 2000 - F. de Alva Ixtlilxochitl Historia de la nación chichimeca, Germán Vázquez Chamorro (ed.), "Crónicas de América", Dastin (Historia), Madrid 2000.

Alvarado Tezozomoc 2001 - H. de Alvarado Tezozomoc Crónica mexicana, Gonzalo Díaz Migoyo y Germán Vázquez Chamorro (eds.), Dastin (Crónicas de América), Madrid 2001.

Alvarado Tezozomoc 1975 - H. de Alvarado Tezozomoc Crónica Mexicayotl, Unam, Instituto de Investigaciones Históricas, México, 1975.

Anales de Cuauhtitlan 1992 - J. Bierhorst (trad.) History and Mythology of the Aztecs. The Codex Chimalpopoca. University of Arizona Press, Tucson 1992.

Anders, JAnSEN y Reyes García 1991 - F. Anders, M. Jansen y L. Reyes García El Libro del Cihuacoatl. Homenaje para el año del Fuego Nuevo. Libro explicativo del llamado Códice Borbónico. "Códices mexicanos III". Sociedad Estatal Quinto Centenario, ADEVA, Fondo de Cultura Económica, México 1991.

BIERHORST 1985 - J. Bierhorst A Nahuatl-English Dictionary of Concordance to the "Cantares Mexicanos". An Analytic Transcription and Grammatical Notes. SUP, Stanford, California 1985

Bотн 2008 - A.A. Both La música prehispánica: Sonidos rituales a lo largo de la historia. "Arqueología Mexicana", vol. XVI, núm. 94, pp. 30-37, Raíces, México 2008.

BURKHART 1992 - L. M. Burkhart Flowery heaven: the aesthetic of paradise in Nahuatl devotional literature. "Res" 21, 1992.

Cantares Mexicanos 1994 -Cantares mexicanos. Manuscrito de la Biblioteca Nacional de México. M. León-Portilla (ed.) Ed. Facs. IIB, Unam, México 1994. 
Chimalpahin Quauhtlehuanitzin 1998 - D. Chimalpahin Quauhtlehuanitzin Las ocho Relaciones y el Memorial de Colhuacán, Rafael Tena (trad.), 2 vols., Conaculta (Cien de México) México 1998.

Chimalpahin Quauhtlehuanitzin 2003 - D. Chimalpahin Quauhtlehuanitzin Séptima Relación, Josefina García Quintana (trad.), Unam, México 2003.

Codex Chimalpahin 1997 - D. Chimalpahin Quauhtlehuanitzin Society and politics in Mexico Tenochtitlan, Tlatelolco, Texcoco, Culhuacan, and other Nahua altepetl in Central Mexico, Susan Schroeder (ed.), 2 tomos, University Of Oklahoma Press, Norman-London 1997.

Códice Borbónico 1980 - Códice Borbónico. Manuscrito mexicano de la biblioteca del Palais Bourbon (Libro adivinatorio y ritual ilustrado), Ed. Facs., Siglo XXI (America Nuestra), México 1980.

Códice Borgia 1963 - Códice Borgia, Eduard Seler (ed.), Fondo de Cultura Económica, México 1963.

Códice Telleriano-Remensis 1995 - Codex Telleriano-Remensis. Ritual, Divination and History in a Pictorial Aztec Manuscript, Eloise Quiñones Keber (ed.), University of Texas Press, Austin 1995.

Códice Tudela 2002 - Códice Tudela. Ed. Facs. Ministerio de Educación, Cultura y Deportes, Madrid 2002.

Credo - J.R. García-Murga Vazquez, El Dios del amor y de la paz, Universidad Pontificia Comillas, p. 238, 1991.

Dehouve 2009 - D. Dehouve "El lenguaje ritual de los mexicas: hacia un método de análisis". En: Image and Ritual in the Aztec World: selected papers of the "Ritual Americas" conferences. Archaeopress: 19-33, Oxford 2009.

Durán 1967 - D. Diego Historia de las Indias de la Nueva España e islas de Tierra Firme, 2 tomos, Porrúa, México 1967 (1581).

G.D.N. (Gran Diccionario en Nahuatl) 2011 - Gran Diccionario Náhuatl. Programa de Marc Thouvenot. Fuente electrónica: http://www.sup-infor. com [varias consultas].

García ICAZBAlCETA 1941 - J. García Icazbalceta Nueva colección de documentos para la historia de México. 3 tomos, Salvador Chavez Hayhoe, México 1941.

GARIBAY 1971 - A.M. Garibay Kintana Historia de la Literatura Náhuatl. 2 tomos Porrúa, México 1971.

Gibson 1960 - Ch. Gibson "The Aztec Aristocracy in Colonial Mexico" En: Comparative Studies in Society and History, Vol. 2, núm. 2, pp. 169196, 1960. 
Graulich 1990 - M. Graulich Mitos y rituales del México antiguo. Angel Barral Gómez (trad.), Ediciones Istmo, Madrid 1990.

GraUlich 2002 - M. Graulich Los reyes de Tollan. "Revista española de antropología americana”, vol. 32: 87-114, 2002.

Guerra 1998 - A. Guerra (ed.) San Francisco de Asís. Escritos. Biografias. Documentos de la época. Biblioteca de Autores Cristianos (BAC 399), Madrid, 1998.

HiLl 1992 - J.H. Hill The Flower World of Old Uto-Aztecan. "Journal of Anthropological Research", Vol. 48, No. 2, pp. 117-144, 1992.

Historia tOLTECA-CHICHIMECA 1947 - Historia tolteca-chichimeca. Anales de Quauhtinchan, H. Berlin (ed.), Antigua Librería Robredo de José Porrúa e hijos, México 1947.

Histoyre du Mexique 2005 - "Histoyre du Mexique" En: Teogonía e historia de los mexicanos. Tres opúsculos del siglo XVI, A.M. Garibay K. (ed.), Porrúa, pp. 90-120, México 2005.

JoHANSSON 2016 - P. Johansson Miccacuicatl: las exequias de los señores mexicas. Primer Circulo, México 2016.

La Biblia de las Americas 1997 - La Biblia de las Americas. Foundation Publications LBLA 1997.

LARA 2016 - J. Lara Birdman of Assisi. Art and the Apocalyptic in the Colonial Andes. ACMRS, Editorial Bilingue, Arizona 2016.

León-Portilla et al. 2011 - Cantares mexicanos I y II. Ed. e introd. de M. León-Portilla, presentación de G. Curiel, estudios de A. Hernández de León-Portilla, L. Villagómez y S. Reyes Equiguas. Paleografía, traducción y notas de M. León-Portilla, L. Silva Galeana, F. Morales Baranda y S. Reyes Equiguas. CH/IIB/IIF/IIH-Unam - Fideicomiso Teixidor, México 2011.

López Austin 1998 - A. López Austin Los mitos del Tlacuache: caminos de la mitología mesoamericana. Unam, Instituto de Investigaciones Antropológicas, México 1998.

LóPEZ DE LA TORRE 2016 - C. F. López de la Torre El trabajo misional de fray Pedro de Gante en los inicios de la Nueva España. "Fronteras de la Historia", vol. 21 no 1, 2016.

MadajCZAK 2006 - J. Madajczak Problem następstwa władzy w środkowym Meksyku podczas konkwisty i w pierwszym dwudziestoleciu okresu kolonialnego. Tesis de maestría (inédita), Universidad de Varsovia, Varsovia 2006.

MADAJCZAK 2014 - J. Madajczak Nahuatl kinship terminology as reflected in colonial written sources from Central Mexico: a system of 
classification. Tesis de doctorado (inédita). Universidad de Varsovia, Varsovia 2014.

Manuscrito Tovar 2001 - J. de Tovar Historia y creencias de los Indios de México, S. Urraca Uribe y J.J. Fuente del Pilar (eds)., Miraguano, Madrid 2001.

Mendieta 1999 - G. de Mendieta Historia ecelsiástica indiana: obra escrita a fines del siglo XVI. Edición digital a partir de la edición de J. García Icazbalceta, Antigua Librería, México 1999 (1870). Fuente electrónica: http://bib.cervantesvirtual.com.

Molina 1992 - A. de Molina Vocabulario en lengua castellana y mexicana y mexicana y castellana, Ed. Porrúa, México 1992 (1571).

Montes De OCA 2000 - M. Montes de Oca Vega Los difrasismos en el náhuatl del siglo XVI. Tesis de doctorado. Facultad de Filosofía y Letras, Unam, México 2000.

NAVARRETE LinARES 2011 - F. Navarrate Linares Los orígenes de los pueblos indígenas del Valle de México. Los altepetl y sus historias. Unam, México 2011.

ONG 1982 - W. J. Ong Orality and Literacy, Routledge, London 1982.

Pepestraete 2008 - S. Pepestraete "El cihuacoatl Tlacaélel: su papel en el imperio azteca y su iconografía”. En: G. Olivier (ed.) Símbolos del poder en Mesoamérica. Unam, México.

Reyes García 2001 - L. Reyes García ¿Cómo te confundes? ¿Acaso no somos conquistados? Anales de Juan Bautista. Biblioteca de Boturini, Insigne y Nacional Basílica de Guadalupe, Ciesas, México 2001.

Ricard 2014 - R. Ricard La conquista espiritual de México, Fondo de Cultura Económica, México 2014.

Sahagún 1950-1982 - B. de Sahagún Florentine Codex. General History of the Things of New Spain, A. J. O. Anderson y Ch. E. Dibble (eds.), The School of American Research - University of Utah, Santa Fe (New Mexico) 1950-1982.

SAHAGún 1988 - B. de Sahagún Historia general de las cosas de Nueva España, 2 tomos, Alianza Editorial, Madrid 1988 [1577].

TeDLock 1996 - D. Tedlock Popol Vuh. The definitive Edition of the Mayan Book of the Dawn of Life and the Glories of Gods and Kings, Simon and Schuster, New York 1996.

Tira de Peregrinación S.F. - Codex Boturini o Tira de Peregrinación, Fuente electrónica: codiceboturini.inah.gob.mx/downloads.php [varias consultas].

WiMmer 2014 - A. Wimmer Dictionnaire de la langue nahuatl classique. Fuente electrónica: http://sites.estvideo.net/malinal 


\section{Summary}

\section{A song in honor of San Francisco or a funerary song for Sebastian Ramirez de Fuenleal? An interpretation of the so called Pipilcuicatl, "The Children's Song", registered in the manuscript of Cantares mexicanos}

The article presents a critical interpretation of one of the songs collected in the $16^{\text {th }}$-century manuscript known as Cantares mexicanos. "The Children's Song", in Nahuatl Pipilcuicatl, is one of the few pieces of this manuscript provided with clear information on the context of its performance, which apparently should facilitate its correct interpretation. However, as the present analysis shows, the song in question is in fact a result of various reelaborations of the more ancient models. It is an overlap of different semantic levels corresponding to diverse ideologies, objectives, events and socio-politic contexts, such as: the ancient indigenous rituals, funerary celebrations, Medieval and Renaissance Christian popular beliefs and aesthetics, as well as the contemporary Colonial aesthetics of the New Spain. The objective of this article is to indicate the possible meanings that might have been attributed to different elements of this song by the Spaniards and the indigenous participants of the celebration.

Keywords: Aztecs, death, oral tradition, songs, funerary rituals

\section{Streszczenie}

Pieśń ku czci św. Franciszka czy pieśń żałobna z okazji pogrzebu Sebastiana Ramireza de Fuenleal? Próba interpretacji tak zwanego Pipilcuicatl, „Pieśni dzieci" z manuskryptu Cantares mexicanos

Celem prezentowanego artykułu jest dokonanie przekładu krytycznego jednego z utworów zebranych w szesnastowiecznym manuskrypcie znanym jako Cantares mexicanos. „Pieśń dzieci”, w języku nahuatl Pipilcuicatl, jest jedną z nielicznych pieśni z tego zbioru, której przypisany został konkretny kontekst przedstawienia, co pozornie w znacznej mierze powinno ułatwić poprawną analizę tekstu. Jednakże jak wykazały przeprowadzone badania, analizowany utwór jest w rzeczywistości przeróbką kilku starszych dzieł. Nakładają się w nim znaczenia pochodzące z różnych kultur, ideologii i kontekstów społeczno-politycznych, między innymi: dawnych rytuałów indiańskich, obrzędów pogrzebowych, wierzeń popularnych rozpowszechnionych w średniowiecznej i wczesnorenesansowej Europie, a także estetyki charakterystycznej dla wczesnokolonialnej Nowej Hiszpanii. Celem prezentowanej pracy jest wskazanie różnorakich znaczeń i możliwych interpretacji elementów symbolicznych zawartych w badanym utworze.

Słowa kluczowe: Aztekowie, śmierć, tradycja oralna, pieśni, rytuały pogrzebowe 